Research Article

\title{
Effect of Multiwalled Carbon Nanotubes and Electroless Copper Plating on the Tensile Behavior of Carbon Fiber Reinforced Polymers
}

\author{
Gia Toai Truong, Jiho Kim, and Kyoung-Kyu Choi $\mathbb{D}$ \\ School of Architecture, Soongsil University, 369 Sangdo-ro, Dongjak-gu, Seoul 06978, Republic of Korea \\ Correspondence should be addressed to Kyoung-Kyu Choi; kkchoi97@gmail.com
}

Received 26 March 2018; Revised 29 May 2018; Accepted 28 June 2018; Published 19 July 2018

Academic Editor: Ilia Ivanov

Copyright (c) 2018 Gia Toai Truong et al. This is an open access article distributed under the Creative Commons Attribution License, which permits unrestricted use, distribution, and reproduction in any medium, provided the original work is properly cited.

\begin{abstract}
Multiwalled carbon nanotubes (MWCNTs) and nanoscaled electroless copper plating were introduced to enhance the mechanical properties of carbon fiber reinforced polymer (CFRP) composites in this study. The influence of multiwalled carbon nanotubes (MWCNTs) with weight fractions of $0.5-1.5 \%$ of epoxy resin on the mechanical properties of CFRP composites was investigated. The MWCNTs and epoxy resin was first mixed, prior to impregnating the carbon fiber fabrics. Electroless copper plating, a deposit method using simultaneous reactions in an aqueous (copper) solution without external electric power, was applied on the carbon fiber surface, and the effect was also investigated. The CFRP test specimens were fabricated by hand lay-up method, using one or three carbon fiber fabrics. The mechanical properties of the CFRP test specimens were derived by tensile tests according to KS M ISO 527-4. According to the morphology taken by SEM, the carbon fiber surface was significantly rough with copper ions. Because of this, the strength and ultimate strain of coated specimens increased up to 26.3 and $18.6 \%$ compared to noncoated specimens, respectively. In addition, as the MWCNTs amount increased, the ultimate strain of the composites also increased. In the case of CFRP test specimens using noncoated carbon fiber fabrics, the addition of $1.5 \%$ wt. MWCNTs increased the peak strength and ultimate strain of CFRP specimens up to 80.5 and $48.8 \%$, respectively. Finally, the tensile stress-strain relationship of CFRP specimens was idealized as bilinear or trilinear response curves.
\end{abstract}

\section{Introduction}

Since the 1960s, carbon fiber reinforced polymer (CFRP) composites have been widely used in a wide range of applications, including the aircraft/aerospace and automotive industries, and civil and architectural engineering. This is because CFRP composites exhibit high strength and stiffness, high thermal stability, and corrosion resistance [1-3]. In addition, since the CFRP composites were primarily fabricated by using carbon fiber fabrics of relatively light weight, the weight of the existing concrete structures after retrofitting by using the composites would not considerably increase. However, one of the most severe problems in fabricating the CFRP composites is the poor interfacial bonding between carbon fiber fabrics and polymeric matrices. Such poor interfacial adhesion could limit the mechanical properties of CFRP composites [4-6]. Ozdemir et al. [7], Velasco-Santos et al. [8], and Agnihotri et al. [9] investigated the use of carbon fiber reinforced polymers without carbon fiber surface treatment resulting in low interlaminate shear strength, which causes poor interfacial bonding between the carbon fibers and polymeric matrices.

Many methods including plasma treatment, acidic treatment, nanoparticle coating, and carbon nanotubes coating have been experimentally carried out to improve and activate the surface of the carbon fibers. Among these methods, growing carbon nanotubes on the carbon fiber fabrics is one of the most popular methods [10-15]. Barua and Saha [10] presented a method to deposit CNTs onto the surface of carbon fibers by using ultrasonic atomization to fabricate hybrid nano-micro fiber composite structures. In this method, multiwalled carbon nanotubes (MWCNTs) 
were first mixed in a solvent (DMF), to prepare CNTsolution. Then, this CNT-solution was sprayed directly onto both sides of carbon fiber fabrics, which were placed on a hot plate at $80^{\circ} \mathrm{C}$ inside a spay chamber, to form hybrid micro-nano composite structures. In the study by Moaseri et al. [11], MWCNT-carbon fiber hybrid material was fabricated through pyrolysis treatment. According to this method, MWCNTs, which were initially dispersed in ultrasonic bath containing ethanol to achieve homogenous suspension, were first deposited onto carbon fiber surfaces by using electrophoretic deposition. Subsequently, MWCNTcarbon fiber hybrid was impregnated in a saturated solution of petroleum pitch to reduce voids, and pyrolized at high temperature. Finally, the MWCNT-carbon fiber hybrid was cleaned by acetone, to remove the residual petroleum pitch. Such hybrid composites after diffusion into the epoxy matrix were shown to increase the flexural strength in comparison with that of the neat composite, and the increase of flexural strength consistently corresponded with increasing the fiber weight fraction of carbon nanotubes $[10,11]$. This is due to the increase of interfacial shear strength (IFSS) of the hybrid composites after deposition of MWCNTs onto the carbon fiber surfaces. For example, Moaseri et al. [11] found that the deposition of MWCNTs onto the carbon fiber surface up to a fiber weight fraction of $8 \%$ could increase the IFSS up to approximately $15.4 \%$. Sharma and Lakkad [14] prepared the hybrid composites by directly growing multiwalled carbon nanotubes (MWCNTs) onto the surface of carbon fiber using a chemical vapor deposition technique under high temperature. In this method, acetylene $\left(\mathrm{C}_{2} \mathrm{H}_{2}\right)$ was presented as catalyst for the deposition process of MWCNTs. From the test results, MWCNTs were coated successfully on the carbon fibers to form multiscale hybrid composites. The presence of MWCNTs on the carbon fiber surface increased the tensile strength of the multiscale hybrid composites (after immersing in epoxy) up to $69 \%$, in comparison with that of the carbon fibers without coating of MWCNTs.

Recently, metal plating has arisen as a method to improve the smooth surface of carbon fibers $(\mathrm{CF})$ and thus enhance the interfacial bonding between carbon fibers and polymer matrices [16-19]. Yan et al. [16] and Park et al. [17] applied an electroless nickel plating method to metalize the carbon fiber surface. In the electroless plating process, the carbon fibers would be soaked into a plating solution containing molten salt to absorb the $\mathrm{Ni}^{2+}$ ions. The test results showed that the nickel amount on the carbon fiber surface was increased with increasing the plating time, and the obtained thickness after coating was measured using nanoscale. When the activation time increased from 4 to 12 minutes, the deposition amount increased from 6,000 to $9,000 \mathrm{mg} / \mathrm{g}$ CF and the thickness of CF after coating was around 2 to $3 \mu \mathrm{m}$ [16], resulting in a carbon fiber surface noticeably rough $[16,17]$. The study by Park et al. [17] found that the formation of Ni-P alloy on carbon fiber surface significantly increased the interlaminated shear strength (ILSS) of the carbon fiber composites. After 10 minutes of plating, the ILSS of the test specimens was $31.7 \mathrm{MPa}$, which was higher than that (approximately $27.5 \mathrm{MPa}$ ) of test specimens without plating. Therefore, the flexural strength of nickel-plated carbon fibers also increased, and showed virtually ductile failure mode. However, in the case of a plating time over 15 minutes, the flexural strength of carbon fiber considerably decreased, due to the decrease of ILSS. In addition, Bottger-Hiller et al. [18] investigated the deposition of carbon fiber surface by multimetallic particles using an electroless plating process. Bottger-Hiller et al. [18] coated carbon fibers with both copper and zinc.

Although the previous methods considerably improved the mechanical behavior of carbon fiber reinforced polymer (CFRP) composites, they required long duration for performance and needed to be considered consistently cost-effective. A number of studies also showed good enhancement in the mechanical properties of CFRP composites when carbon fiber surface was directly coated with polymer matrices-added carbon nanotubes (CNTs) or carbon nanofibers (CNFs) [20-23]. Soliman et al. [21] investigated the effect of carbon functionalized multiwalled carbon nanotubes (COOH-MWCNTs) on the behavior of carbon-woven fabric composite plates. The test results found that with $1.5 \% \mathrm{COOH}-\mathrm{MWCNTs}$, the off-axis flexural strength and modulus increased up to 28 and $19 \%$, respectively. In addition, the shear toughness of carbon-woven composites tested in shear increased by $33 \%$. Zhou et al. [23] tested the flexural, tensile, and fatigue behaviors of satin weave carbon fabric composites. The test results indicated that when $2 \%$ wt. CNF was added into epoxy matrix, the flexural and tensile strengths of the composites increased approximately 22.3 and $11 \%$, respectively. Moreover, the fatigue performance of the satin weave carbon fabric composites was also enhanced. Furthermore, Yao et al. [24] determined the interfacial shear strength (IFSS) of T700 grade carbon fiber composites by tests. It was reported that the use of different matrices with the addition of different types of carbon nanotubes significantly affected the IFSS. In the case of epoxy (EP) matrix, desized fibers exhibited less IFSS than did sized fibers; meanwhile, in the cases of bismaleimide (BMI) matrix, desized fibers exhibited higher IFSS than sized fibers.

In this study, the effects of nanoscaled electroless copper plating and multiwalled carbon nanotubes (MWCNTs) on the mechanical properties of carbon fiber reinforced polymer (CFRP) composites with epoxy matrix were investigated through tensile tests. The amount of MWCNTs used was 0.5, 1 , and $1.5 \%$ by weight. The test specimens were fabricated by hand lay-up method, using one or three carbon fiber fabrics. The morphology taken by scanning electron microscopy (SEM) was used to analyze the carbon fiber surface after electroless plating. The mechanical properties of carbon fiber reinforced polymer (CFRP) test specimens were estimated in terms of the initial stiffness, peak strength, and ultimate strain.

\section{Experimental Program}

2.1. Material Properties. In this study, the carbon fiber fabric used was T300-3000 with $3 \mathrm{k}$ filaments. According to the database given by the manufacturer, the carbon fiber fabrics have a thickness of $0.21 \mathrm{~mm}$ with a filament diameter of 
TABLE 1: Chemical compounds of electroless copper plating.

\begin{tabular}{lcc}
\hline Process & Chemical compounds & Amount \\
\hline \multirow{4}{*}{ Activation of carbon fiber } & $\mathrm{HNO}_{3}(65-68 \%)$ & $200 \mathrm{~mL} / \mathrm{L}$ \\
fabrics & $\mathrm{SnCl}_{2}(90 \%)$ & $50 \mathrm{~g} / \mathrm{L}$ \\
& $\mathrm{HCl}^{(35-36 \%)}$ & $80 \mathrm{~mL} / \mathrm{L}$ \\
& $\mathrm{AgNO}_{3}(99 \%)$ & $20 \mathrm{~g} / \mathrm{L}$ \\
\hline & $\mathrm{CuSO}_{4} \cdot 5 \mathrm{H}_{2} \mathrm{O}(99 \%)$ & $22 \mathrm{~g} / \mathrm{L}$ \\
Copper plating bath & $\mathrm{C}_{6} \mathrm{H}_{5} \mathrm{Na}_{3} \mathrm{O}_{7} \cdot 2 \mathrm{H}_{2} \mathrm{O}$ & $56 \mathrm{~g} / \mathrm{L}$ \\
& $(99 \%)$ & $0.6 \mathrm{~g} / \mathrm{L}$ \\
& $\mathrm{NaOH}^{2}(93 \%)$ & $44 \mathrm{~mL} / \mathrm{L}$ \\
\hline Cleaning & $\mathrm{N}_{2} \mathrm{H}_{4} \cdot \mathrm{H}_{2} \mathrm{O}(98 \%)$ & \\
\hline
\end{tabular}

$7 \mu \mathrm{m}$, a tensile strength of $3,530 \mathrm{MPa}$, an elastic modulus of $230,000 \mathrm{MPa}$, and an ultimate tensile strain of $1.5 \%$. The carbon fiber fabric has a density and weight of $1.76 \mathrm{~g} / \mathrm{cm}^{3}$ and $198 \mathrm{~g} / 1000 \mathrm{~m}$, respectively. The type of carbon fiber fabrics used in this study is relatively light, compared to other types of carbon fiber fabrics.

The multiwalled carbon nanotubes (MWCNTs) used in this study were manufactured by a high technology with purity of up to $90 \mathrm{wt} . \%$. The diameter of MWCNTs was 5-20 $\mathrm{nm}$, and the average length was $10 \mu \mathrm{m}$; thus, the aspect ratio (length divided by diameter) is in the range 500 to 2,000 . The tensile strength and elastic modulus of MWCNTs were $100 \mathrm{GPa}$ and $1,280 \mathrm{GPa}$, respectively, as given by the manufacturer. In comparison with other types of nanomaterials, such as single-walled CNTs, $\mathrm{xGnP}$, and CT3, MWCNTs are widely used, due to their low cost.

The epoxy resin YD-115CA, which is a Bisphenol-A type liquid diluted with butyl glycidyl ether (BGE), was used in this study as an adhesive material. The use of YD-115CA is due to its good adhesive strength, chemical resistance after curing, high reactivity, and in particular, low viscosity. The viscosity of this epoxy is about 800 to $1,600 \mathrm{cps}$ at $25^{\circ} \mathrm{C}$. Such low viscosity of epoxy allows it to be easily absorbed into carbon fiber fabrics during the fabrication process. G-A0533, a low viscosity polyamidoamine resin, was used as curing agent (or hardener). At $25^{\circ} \mathrm{C}$, the viscosity of this curing agent is about 500 to $1,000 \mathrm{cps}$. The stoichiometric ratio between YD-115CA and G-A0533 was 100:55 by weight, and the curing time of the mixing was two hours at $80^{\circ} \mathrm{C}$.

2.2. Electroless Copper Plating Process. The carbon fiber fabrics (or carbon fibers) were used as the substrate, and the electroless copper plating bath contained $22 \mathrm{~g} / \mathrm{L}$ of copper sulphate $\left(\mathrm{CuSO}_{4} \cdot 5 \mathrm{H}_{2} \mathrm{O}\right)$ as a source of copper ions. The amount of sodium hydroxide $(\mathrm{NaOH})$ used was $0.6 \mathrm{~g} / \mathrm{L}$, to ensure the $\mathrm{pH}$ value of the copper bath would reach 12 . The $\mathrm{pH}$ of an electroless copper bath will influence the speed and brightness of the copper deposit. Thus, a $\mathrm{pH}$ value above 12 is preferred, although it could result in poor solution stability, and reduce the copper bath life [25]. Table 1 provides the details of the chemical compounds used for the electroless plating.

The copper plating process was primarily performed based on the studies by Dehkharghani and Divandari [26], and Chen et al. [27]. Figure 1 shows the process of electroless copper plating applied in this study. The figure shows that the electroless copper plating process included three major steps, as follows: activation of carbon fiber fabrics, carbon fiber fabrics coating, and cleaning. Prior to being plated, the carbon fiber fabrics were soaked in a solution containing $200 \mathrm{~mL} / \mathrm{L}$ of nitric acid (HNO3, 65-68\%) and stirred at $90^{\circ} \mathrm{C}$ for $30 \mathrm{~min}$. The purpose is to degrease the surface of the carbon fiber fabrics and thus improve the interfacial adhesive between copper coating and carbon fiber fabrics [17]. After rinsing in distilled water, the carbon fiber fabrics were soaked in a solution containing $50 \mathrm{~g} / \mathrm{L}$ of tin (II) chloride $\left(\mathrm{SnCl}_{2}\right)$ and $80 \mathrm{~mL} / \mathrm{L}$ of hydrochloric acid $(\mathrm{HCl}, 35-36 \%)$, to sensitize them. This stage was carried out at a temperature of $35^{\circ} \mathrm{C}$ for 15 minutes. The carbon fiber fabrics with sensitizing treatment were then rinsed in distilled water, to prepare for the next activation step. In the activation step, a solution composed of $20 \mathrm{~g} / \mathrm{L}$ silver nitrate $\left(\mathrm{AgNO}_{3}, 99 \%\right)$ and $80 \mathrm{~mL} / \mathrm{L}$ of hydrochloric acid ( $\mathrm{HCl}, 35-36 \%)$ was used. In this stage, the carbon fiber fabrics were stirred for 15 minutes and then rinsed in distilled water. Finally, such carbon fiber fabrics were immersed in the copper plating bath at $80^{\circ} \mathrm{C}$, and the plating process was carried out within 15 minutes. The component parts of the copper plating bath consist of $22 \mathrm{~g} / \mathrm{L}$ copper sulphate $\left(\mathrm{CuSO}_{4} \cdot 5 \mathrm{H}_{2} \mathrm{O}, 99 \%\right), 56 \mathrm{~g} / \mathrm{L}$ sodium citrate $\left(\mathrm{C}_{6} \mathrm{H}_{5} \mathrm{Na}_{3} \mathrm{O}_{7} \cdot 2 \mathrm{H}_{2} \mathrm{O}, 99 \%\right), 0.6 \mathrm{~g} / \mathrm{L}$ sodium hydroxide $(\mathrm{NaOH}, 93 \%)$, and $44 \mathrm{~mL} / \mathrm{L}$ hydrazine $\left(\mathrm{N}_{2} \mathrm{H}_{4} \cdot \mathrm{H}_{2} \mathrm{O}, 98 \%\right)$. At the end of the plating process, the carbon fiber fabrics were collected, and boiled with acetone $\left(\mathrm{C}_{3} \mathrm{H}_{6} \mathrm{O}, 99.7 \%\right)$ at $70^{\circ} \mathrm{C}$ for two hours, to remove residual chemicals during the plating process. After washing with distilled water, the carbon fiber fabrics were dried in electric heating furnace at $120^{\circ} \mathrm{C}$ for two hours, prior to being used to make test specimens.

2.3. Epoxy-MWCNTs Nanocomposite Test Specimens. To fabricate the CFRP composites, the epoxy resin and MWCNTs mixture were first prepared. The amounts of MWCNTs used in this test are $0.5,1$, and $1.5 \%$ by weight. After adding the amount of MWCNTs into the epoxy resin as required, the mixture was sonicated by a sonicator machine for 30 minutes at $30^{\circ} \mathrm{C}$. This work is to disperse the carbon nanotubes more effectively into the epoxy resin, due to the reduction of the epoxy resin viscosity after heating [28]. After that, the curing agent (or hardener) was added into the mixture of epoxy resin and MWCNTs, and stirred steadily, to form epoxy-MWCNTs nanocomposites, prior to coating on the surface of carbon fiber fabrics.

Figure 2 shows the details of the epoxy-MWCNTs nanocomposite test specimens. Figure 2(a) shows that the epoxy-MWCNTs nanocomposite (or epoxy) test specimen is in dog-bone shape, with a body cross section of $10 \mathrm{~mm}$ width and $4 \mathrm{~mm}$ depth and a length of $80 \mathrm{~mm}$. A silicon mold was used to make such epoxy test specimen (Figure 2(b)). The use of silicon mold is to avoid the adhesive bonding with epoxy, and it could also be exposed to high temperature without fusibility. After mixing, the epoxy-MWCNTs nanocomposite was poured into the mold and then cured at $80^{\circ} \mathrm{C}$ for two hours in electric heating furnace. As mentioned above, the main parameter of the epoxy tensile test is the amount of MWCNTs 


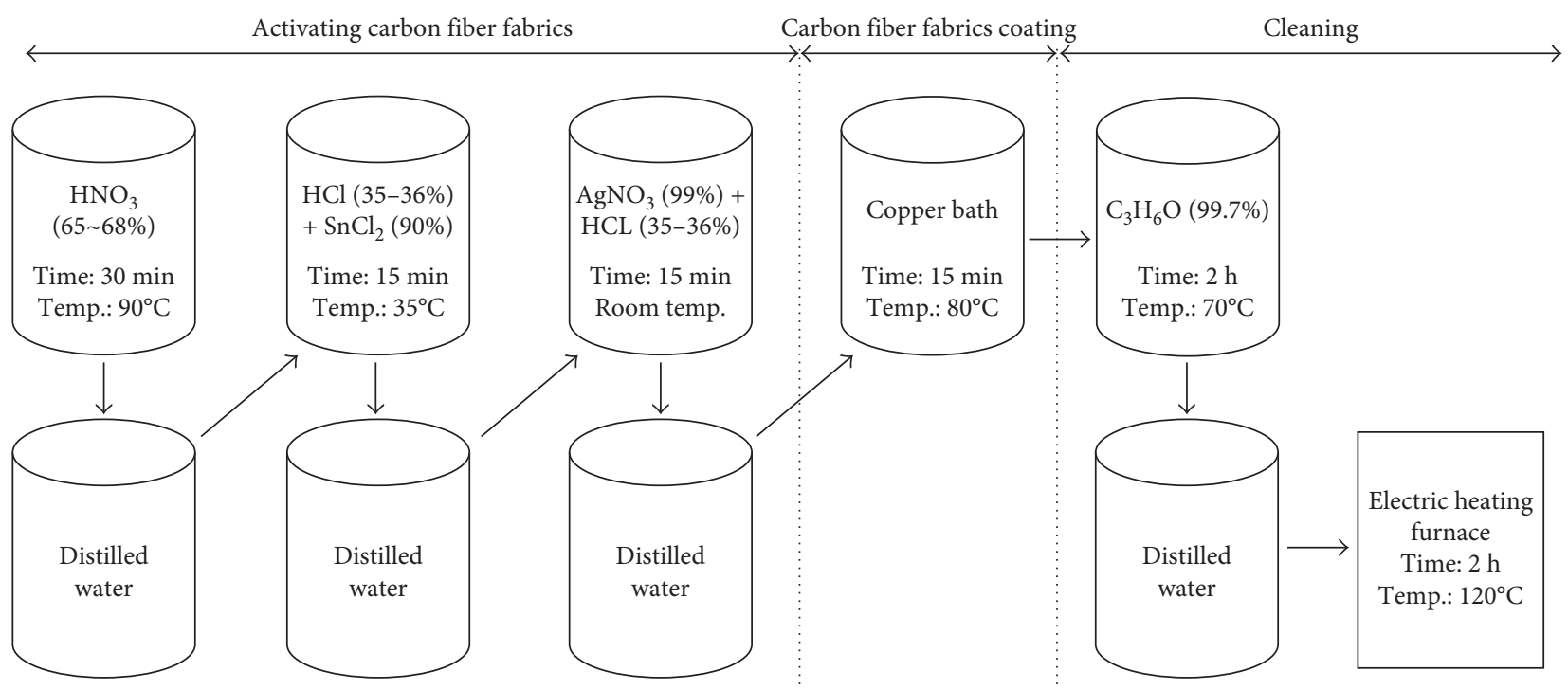

Figure 1: Electroless copper plating process for carbon fiber fabrics.

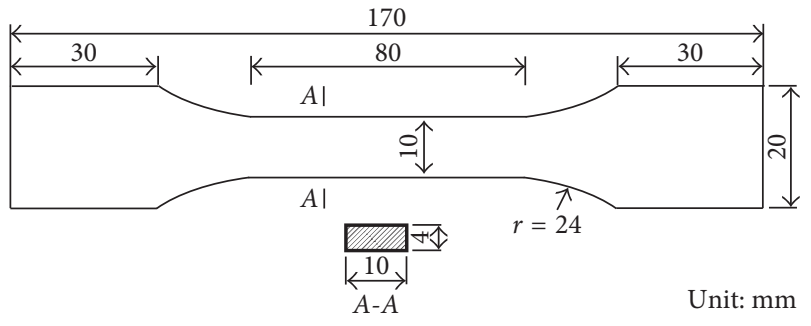

(a)

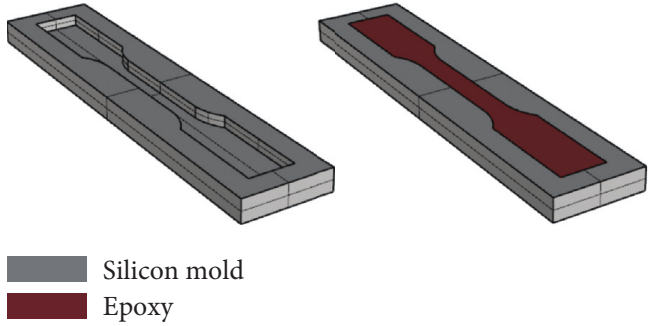

(b)

Figure 2: Tensile test specimen of epoxy. (a) Epoxy test specimen. (b) Epoxy mold.

by weight including $0,0.5,1$, and $1.5 \%$, and thus E-MWCNT-0, E-MWCNT-0.5, E-MWCNT-1, and E-MWCNT-1.5 indicate the epoxy-MWCNTs nanocomposites with $0,0.5,1$, and $1.5 \%$ weight fraction multiwalled carbon nanotubes, respectively. The tensile test of epoxy-MWCNTs nanocomposites (E-MWCNT) was carried out according to the test standard KS M ISO 527-2 [29]. Load applied to the specimens was in a displacement-controlled manner, with a loading rate of $1 \mathrm{~mm} / \mathrm{min}$, up to failure of the test specimen.

2.4. Carbon Fiber Fabric Test Specimens. Figure 3(a) shows the details of the carbon fiber fabric test specimens. The carbon fiber fabric test specimens had a width of $30 \mathrm{~mm}$ and a body length of $150 \mathrm{~mm}$. The use of glass fiber reinforced polymer (GFRP) tabs at two ends of the test specimen is to avoid slippage during testing and to ensure that failure could occur at the tensile measurement zone. Tensile test of carbon fiber fabric was performed in accordance with KS L 2522 standard [30], with a testing speed of $200 \mathrm{~mm} / \mathrm{min}$ (Figure 3(b)).

\subsection{Carbon Fiber Reinforced Polymer (CFRP) Test Specimens.} Figure 4 shows the details of the CFRP test specimens. Figure 4(a) shows that a CFRP specimen has a width of $25 \mathrm{~mm}$ and a body length of $150 \mathrm{~mm}$. At the two ends of the test specimen, glass fiber reinforced polymer (GFRP) tabs were also used to avoid slippage during testing and to ensure that the failure could occur at the tensile measurement zone. In this study, four test series were fabricated, of CFRP-1C, CFRP-3C, CFRP-1NC, and CFRP-3NC. The terms "1C" and " $3 \mathrm{C}$ " indicate that the CFRP test specimen was made from one and three coated carbon fiber layers, respectively. The coating (plating) material is the copper solution, and the plating process is introduced in Electroless Copper Plating Process. Similarly, the terms "1NC" and "3NC" indicate the CFRP test specimen was made from one and three noncoated carbon fiber layers, respectively. Figures 4(b) and 4(c) present the structures of the CFRP test specimens used in this study. In addition, the main parameter in each test series is the amount of MWCNTs mixed in epoxy. Thus, a number indicating the amount of MWCNTs was added to distinguish them. For example, CFRP-1C-0 indicates that the CFRP test specimen was made from one coating of CFRP (1C) and epoxy with $0 \%$ weight fraction of MWCNTs. Tensile test of the CFRP test specimens was carried out based on the guidance specified in test standard KS M ISO 527-4 [31], with a testing velocity of $1 \mathrm{~mm} / \mathrm{min}$ (Figure $4(\mathrm{~d})$ ).

A hand lay-up technique was utilized to make the CFRP test specimens. First, a slight epoxy layer was coated on the surface of silicon plate. The use of silicon plate is to avoid 


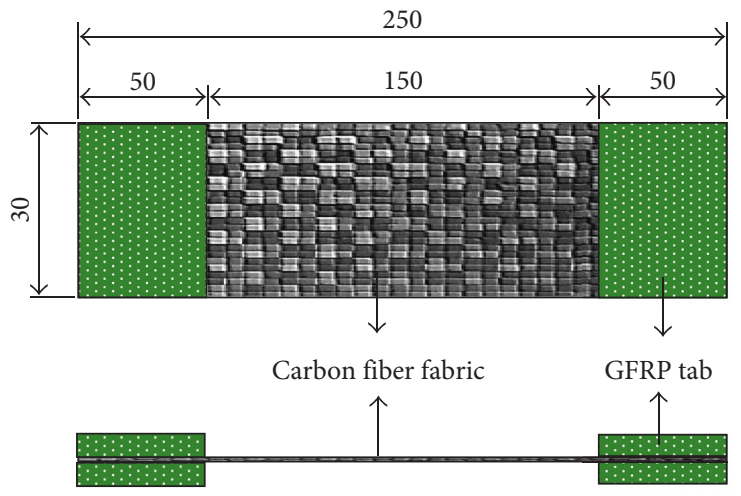

(a)

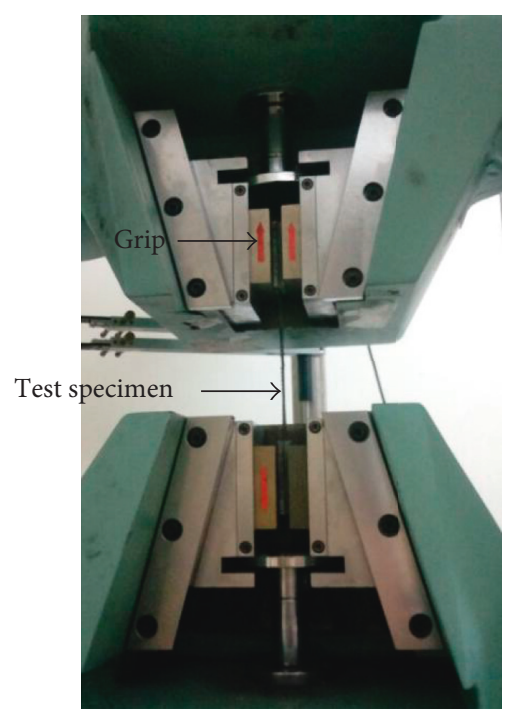

(b)

Figure 3: Tensile test of carbon fiber fabric specimens. (a) Carbon fiber fabric specimen. (b) Test setup, unit: mm.

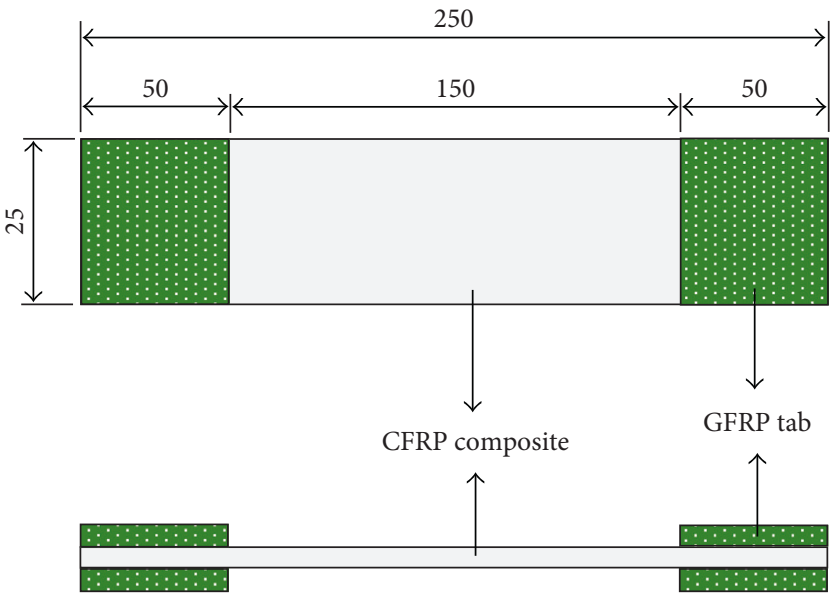

(a)

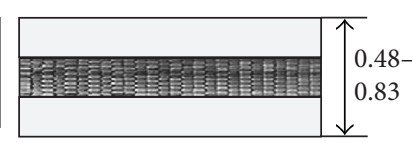

(b)

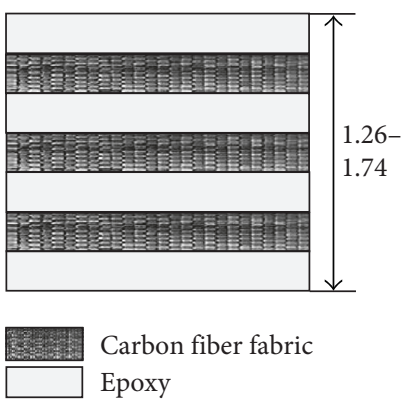

(c)

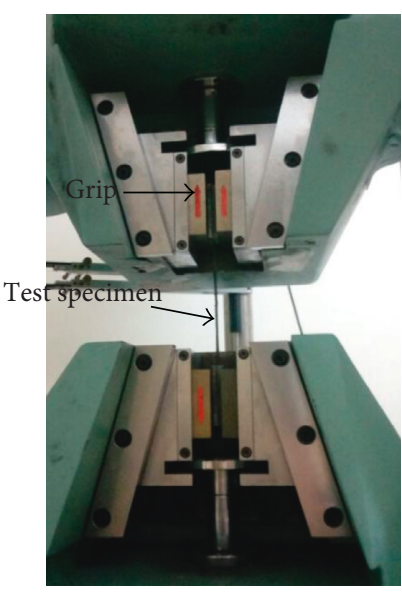

(d)

FIgURe 4: Tensile test of carbon fiber reinforced polymer (CFRP) composites. (a) CFRP test specimen. (b) Section of test specimen with one carbon fiber layer. (c) Section of test specimen with three carbon fiber layers. (d) Test setup, unit: mm.

adsorbing the epoxy, and it could keep the test specimens away from the interfacial adhesion with the base. Then, a carbon fiber layer was manually placed on the silicon base, and the laminating epoxy was applied by brushing. Similarly, subsequent carbon fiber layers were added to fabricate the CFRP test specimens as required. Finally, such CFRP test specimen was cured at $80^{\circ} \mathrm{C}$ for two hours in electric heating furnace, and then was carved to test specimens, as shown in Figure 4(a), to perform the tensile test.

\section{Test Results and Discussions}

3.1. Surface Morphology of the Carbon Fiber Filament. Electroless copper plating is a nongalvanic plating method that does not use external electric power to produce a deposit on a substrate. In this method, metal ions would be deposited on the substrate, depending on simultaneous reactions in an aqueous solution. The surface morphology of the carbon fiber after copper coating was demonstrated by using the Scanning Electron Microscopy (SEM) method. Figure 5 shows the SEM image of a coated carbon fiber fabric in this study. The figure shows that the electroless copper plating process could be successfully applied to carbon fiber fabric. The surface of the carbon fiber filament after coating (plating) was significantly rough, due to the appearance of copper ions. Such surface roughness is expected to considerably improve the interfacial adhesion between carbon fiber and epoxy [32, 33]. In addition, several aggregated phases were also formed on the carbon fiber filament surface, which is attributed to the excess of copper ions. Such excess of copper ions was expected to be due to the long duration of the plating process; thus, further research about the effect of plating time is needed to better understand this behavior. 


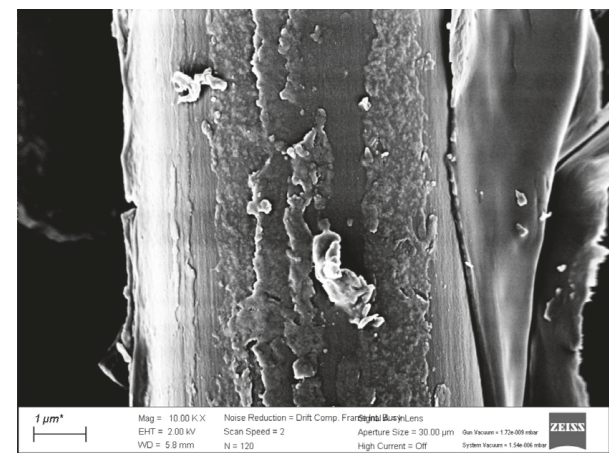

Figure 5: Carbon fiber filament surface after coating.

3.2. Tensile Properties of Epoxy. Figure 6 shows the applied load-strain and stress-strain relationships of the epoxy test specimens with MWCNTs. The control specimen E-MWCNT-0 displays ductile behavior. At the start, it presents a linear elastic behavior, and then extends the deformation through plastic behavior, up to fracture. In general, E-MWCNT-0.5 specimen with a small amount $(0.5 \%)$ of MWCNTs showed almost the same mechanical behavior as that of the control specimen E-MWCNT-0; meanwhile, the specimens E-MWCNT-1 and E-MWCNT-1.5 with 1 and 1.5\% weight fraction of MWCNTs exhibited a significant improvement of mechanical behavior, including peak load and initial stiffness but showed more brittleness than that of E-MWCNT-0.

From the test results obtained in this study, the average initial stiffness, peak strength, and ultimate strain of E-MWCNT-0 were $1.10 \mathrm{GPa}, 25.25 \mathrm{MPa}$, and $8.1 \%$, respectively. In the case of specimen E-MWCNT-0.5, the addition of $0.5 \%$ MWCNTs into epoxy matrix did not display considerable difference of initial stiffness $(1.21 \mathrm{GPa})$, peak strength $(25 \mathrm{MPa})$, or ultimate strain $(8.4 \%)$, compared to those of E-MWCNT-0. Zhang et al. [34] investigated the low amount of carbon nanotubes not inducing noticeable enhancement of epoxy-MWCNTs nanocomposite stiffness. Meanwhile, adding a higher amount of MWCNTs (1 and $1.5 \%)$ significantly increased both the initial stiffness and the peak strength. The initial stiffness of specimens E-MWCNT-1 and E-MWCNT-1.5 was 1.74 and $1.92 \mathrm{GPa}$, respectively. The peak strengths of specimens E-MWCNT-1 and E-MWCNT1.5 were 29 and $39 \mathrm{MPa}$, respectively. In contrast, the ultimate strains of specimen E-MWCNT-1 and E-MWCNT-1.5 show significant reduction. The average ultimate strain of E-MWCNT- 1 was $2.2 \%$ and that of E-MWCNT- 1.5 was $2.4 \%$. For all that, the ultimate strain values of E-MWCNT-1 and E-MWCNT-1.5 obtained in this study were relatively high, compared to other studies $[35,36]$. According to the studies of Rahmanian et al. [37] and Martone et al. [38], such differences in mechanical behaviors of epoxy-MWCNTs nanocomposite test specimens were due to the dispersion morphology of the carbon nanotubes. When a higher amount of MWCNTs was added and dispersed into the epoxy, it could enhance the tensile stress transferring across the cracks and thus lead to increase of the strength of test specimens. Note again that the temperature and duration applied to all epoxy and MWCNTs mixtures were the same.

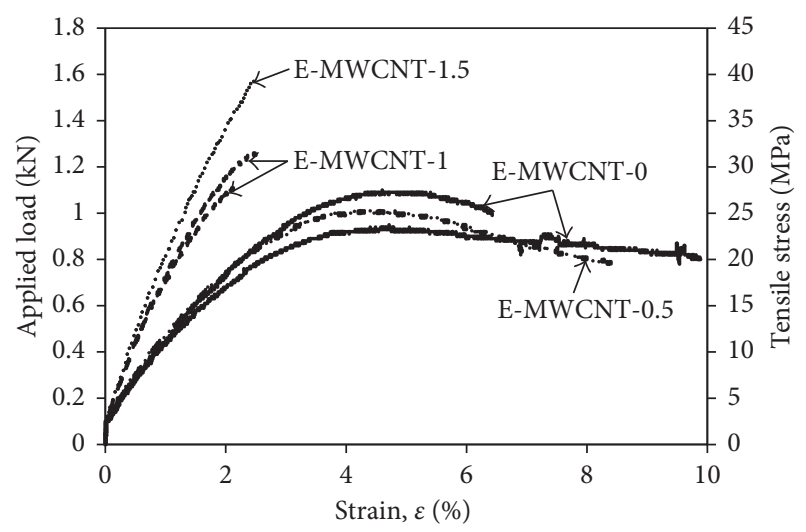

FIGURE 6: Tensile behavior of epoxy with various amounts of MWCNTs.

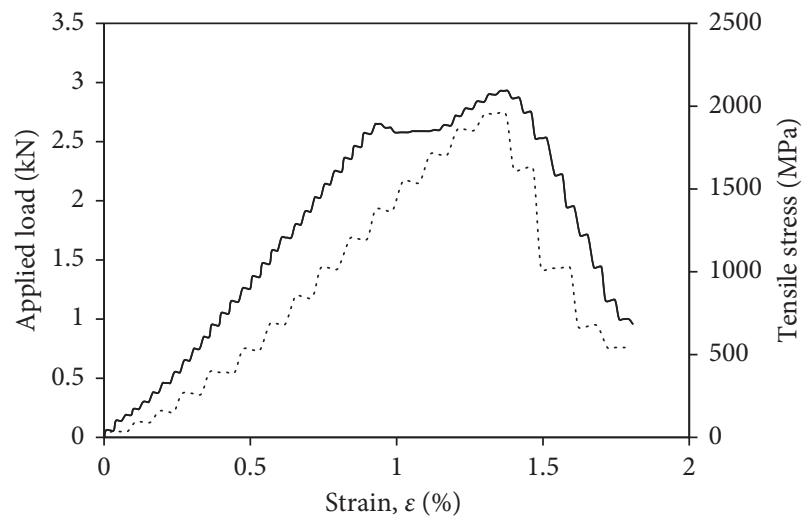

Figure 7: Tensile strength of carbon fiber fabrics.

3.3. Tensile Test Results of Carbon Fiber Fabrics. Figure 7 shows the applied load-strain and stress-strain relationship after tensile test of the conventional carbon fiber fabrics without treatment of electroless copper plating and MWCNTs. Note that in this study, two test specimens of carbon fiber fabrics were tested. The average peak load of carbon fiber fabrics was $2.67 \mathrm{kN}$, corresponding to a tensile strength of $1,950.6 \mathrm{MPa}$, and the average strain at the peak strength of the carbon fiber fabrics was $1.34 \%$. These obtained test results are less than the values given by the manufacturers.

\subsection{Interfacial Characteristics of CFRP Test Specimens.} The surface morphology of CFRP test specimens after coating with epoxy-MWCNTs nanocomposites was demonstrated by the SEM method. Figure 8 shows a typical SEM image at the cross section of test specimen CFRP 1NC-0, which was fabricated by one noncoated carbon fiber layer and epoxy matrix. The figure shows that the epoxy matrix was consistently interlocked with the carbon fiber surface. All surfaces of carbon fiber fabrics were well coated with epoxy matrix. Similarly, in the case of specimen CFRP 3C-1 (Figure 9), which was made from three coatings of carbon fiber layers and epoxy-MWCNTs nanocomposite, the carbon fiber fabrics were also well impregnated with epoxy-MWCNTs 


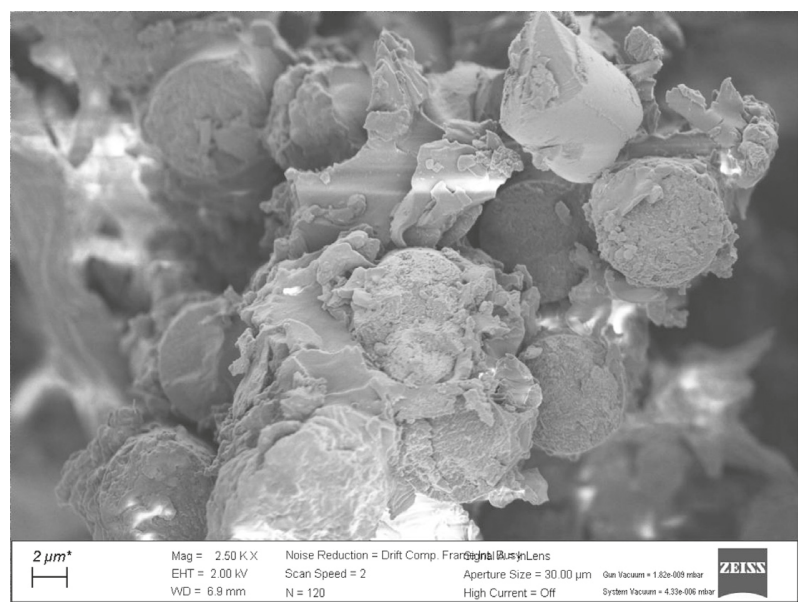

FIGURE 8: SEM images at cross section of specimen CFRP 1NC-0.

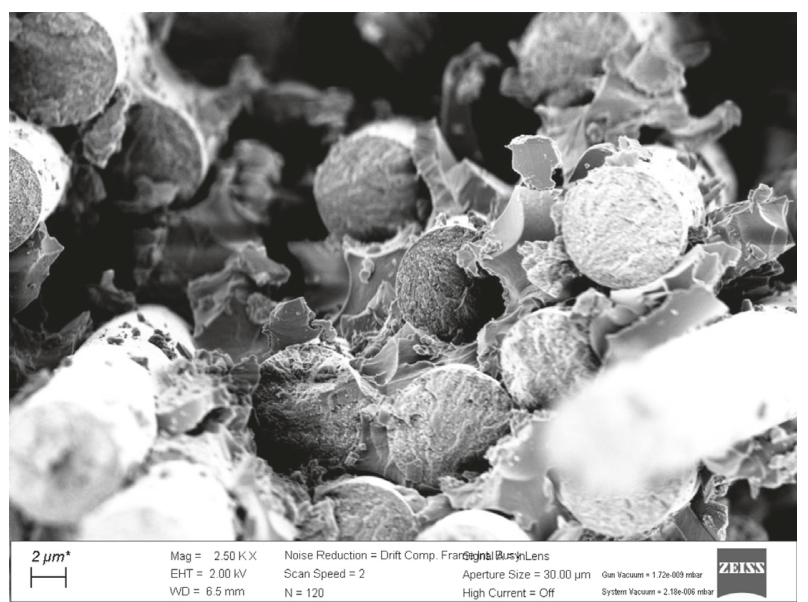

Figure 9: SEM images at cross section of specimen CFRP 3C-1.

nanocomposite. This fact indicates that the hand lay-up method was effectively used to fabricate CFRP test specimens, and the good interfacial bonding between carbon fiber surface and epoxy or epoxy-MWCNT nanocomposite is expected to improve the mechanical behaviors of CFRP composites.

3.5. Tensile Behaviors of CFRP Test Specimens. Figures 10-14 and Table 2 show the applied load-strain and stress-strain responses of the CFRP test specimens. In general, all test specimens showed brittle failure, with a sudden drop after reaching the peak strength $\left(\sigma_{\mathrm{u}}\right)$. Thus, in this study, the ultimate strain $\left(\varepsilon_{\mathrm{u}}\right)$ of a test specimen is defined as the strain obtained at peak strength. In addition, the tensile stresses of the test specimens were determined by dividing the applied load by the total area of carbon fiber fabrics.

Figure 10 shows the applied load-strain and stress-strain responses of the test specimens in the CFRP $1 \mathrm{NC}$ series. The figure shows that the initial stiffness $\left(E_{1}\right)$ of specimens CFRP $1 \mathrm{NC}-1$ and CFRP 1NC-1.5 revealed noticeable increases, compared to that of CFRP 1NC-0. The initial stiffness of CFRP 1NC-0 was $46.9 \mathrm{GPa}$, while those of CFRP 1NC-1 and CFRP 1NC-1.5 were 54.7 and $52.1 \mathrm{GPa}$, respectively

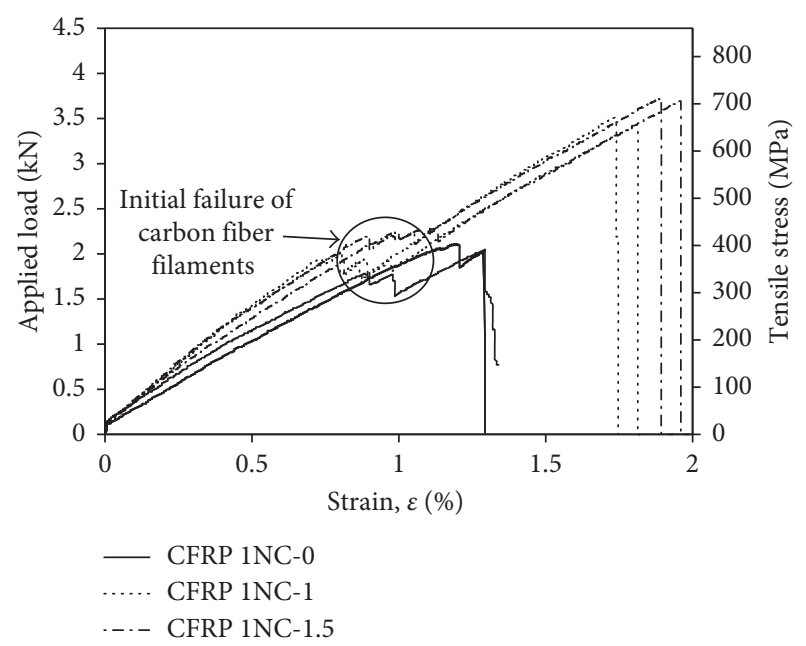

FIgURE 10: Tensile behavior of CFRP test specimens using one noncoated carbon fiber layer.

(Table 2). In addition, the peak strength and ultimate strain of specimens CFRP 1NC-1 and CFRP 1NC-1.5 were also greater than those of CFRP $1 \mathrm{NC}-0$. The peak strength and ultimate strain of control specimen CFRP $1 \mathrm{NC}-0$ were $390.5 \mathrm{MPa}$ and $1.29 \%$, respectively (Table 2). The increases of the peak strengths due to the addition of 1 and $1.5 \%$ MWCNTs were $68.8 \%$ for CFRP $1 \mathrm{NC}-1$, and $80.5 \%$ for CFRP 1NC-1.5, respectively. The increases of the ultimate strains due to the addition of 1 and $1.5 \%$ MWCNTs were $37.6 \%$ for CFRP $1 \mathrm{NC}-1$, and $48.8 \%$ for CFRP $1 \mathrm{NC}-1.5$, respectively. According to the study by Kandare et al. [39], in the CFRP composites, carbon fibers may carry almost all the tensile stress, but epoxy matrix still plays an important role in transferring stresses between carbon fibers. Consequently, once cracks occur in the epoxy matrix, this could lead to subsequent propagation in debonding between carbon fiber fabrics and epoxy matrix and finally result in failure of the CFRP composite. Therefore, the addition of MWCNTs could help to partially arrest the development of cracks in the epoxy matrix and thus increase the loadcarrying capacity of the epoxy matrix, due to the enhancement of the interfacial bonding at the interface between carbon fiber fabrics and the epoxy matrix [40]. Moreover, Figure 10 shows sudden load drops in the loadstrain curves, marked by circles, which indicate the initial failure of several carbon fiber filaments. The fact was attributed to the increasing of the tensile stresses when minor cracks of epoxy matrix had appeared during the loading process.

Figure 11 shows the applied load-strain and stress-strain behavior of CFRP test specimens in series CFRP 3NC. In the figure, the initial stiffness $\left(E_{1}\right)$ of the test specimens in series CFRP $3 \mathrm{NC}$ was slightly improved, due to the increase of the MWCNTs amount (Table 2). The addition of MWCNTs could also increase the peak strength and ultimate strain. Table 2 shows that the peak strengths of specimens CFRP 3NC-1 and CFRP 3NC-1.5 were 715.3 and $737.1 \mathrm{MPa}$, respectively, and were greater than that of CFRP 3NC-0 (669.6 MPa). The addition of 1 and 1.5\% MWCNTs also 
TABLE 2: Tensile test results of CFRP test specimens.

\begin{tabular}{|c|c|c|c|c|c|c|c|c|c|}
\hline \multirow{2}{*}{ Specimens } & \multicolumn{3}{|c|}{ Stage 1} & \multicolumn{3}{|c|}{ Stage 2} & \multicolumn{3}{|c|}{ Stage 3} \\
\hline & $E_{1}(\mathrm{GPa})$ & $\sigma_{1}(\mathrm{MPa})$ & $\varepsilon_{1}(\%)$ & $E_{2}(\mathrm{GPa})$ & $\sigma_{2}(\mathrm{MPa})$ & $\varepsilon_{2}(\%)$ & $E_{3}(\mathrm{GPa})$ & $\sigma_{\mathrm{u}}(\mathrm{MPa})$ & $\varepsilon_{\mathrm{u}}(\%)$ \\
\hline CFRP 1NC-0 & 46.9 & 339.0 & 0.88 & 41.5 & 293.3 & 0.99 & 39.4 & 390.5 & 1.29 \\
\hline CFRP 1NC-1 & 54.7 & 370.5 & 0.83 & 20.3 & 336.2 & 0.92 & 40.8 & 659.1 & 1.78 \\
\hline CFRP 1NC-1.5 & 52.1 & 421.0 & 0.94 & 9.9 & 405.7 & 1.09 & 38.3 & 704.8 & 1.92 \\
\hline CFRP 3NC-0 & 48.9 & 117.5 & 0.24 & - & - & - & 19.5 & 669.6 & 3.06 \\
\hline CFRP 3NC-1 & 51.1 & 129.8 & 0.26 & - & - & - & 19.0 & 715.3 & 3.34 \\
\hline CFRP 3NC-1.5 & 48.2 & 75.6 & 0.13 & - & - & - & 20.2 & 737.2 & 3.40 \\
\hline CFRP 1C-0 & 41.7 & 338.6 & 1.03 & 14.5 & 371.4 & 1.13 & 32.5 & 493.3 & 1.53 \\
\hline CFRP 1C-0.5 & 54.5 & 397.2 & 0.84 & 29.0 & 368.6 & 0.94 & 32.8 & 602.9 & 1.58 \\
\hline CFRP 1C-1 & 43.3 & 525.7 & 1.29 & 110.4 & 470.5 & 1.34 & 27.7 & 565.1 & 1.63 \\
\hline CFRP 3C-0 & 44.3 & 245.1 & 0.52 & - & - & - & 16.4 & 506.0 & 2.11 \\
\hline CFRP 3C- 0.5 & 43.4 & 203.2 & 0.45 & - & - & - & 17.3 & 606.7 & 2.78 \\
\hline CFRP 3C-1 & 53.4 & 255.9 & 0.54 & - & - & - & 14.9 & 521.3 & 2.32 \\
\hline
\end{tabular}

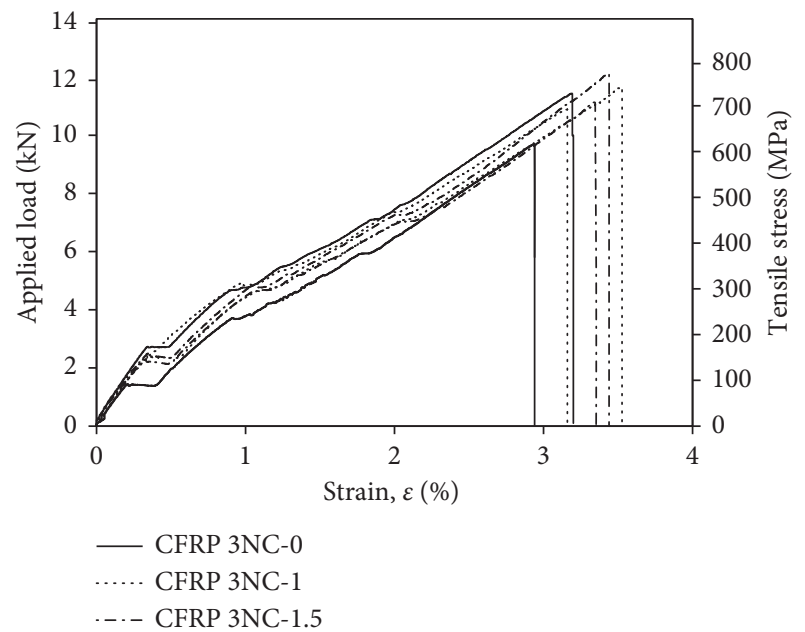

FIgURE 11: Tensile behavior of CFRP test specimens using three noncoated carbon fiber layers.

increased the ultimate strain of CFRP $3 \mathrm{NC}-1$ and CFRP $3 \mathrm{NC}-1.5$ approximately 9.2 and $11.1 \%$, respectively. From the test results of test specimens in the CFRP 1NC and CFRP $3 \mathrm{NC}$ series, it is obvious that the contribution of epoxy matrix to the tensile behavior of CFRP composites was considerable. However, in the case of three layers of carbon fiber fabrics, the increase of the peak strength was not considerable, compared to that in the case of one carbon fiber layer.

Figure 12 compares the tensile behavior of CFRP test specimens using one coated and noncoated carbon fiber fabric. The figure shows that after coating, specimen CFRP $1 \mathrm{C}-0$ using a coating of carbon fiber fabric exhibited both higher peak strength and ultimate strain, compared to those of specimen CFRP 1NC- 0 . The differences estimated were approximately $26.3 \%$ for the peak strength, and $18.6 \%$ for the ultimate strain, respectively. Obviously, this is due to the rough surface of carbon fiber fabrics (Figure 5), after electroless plating contributed significantly to the improvement of interfacial adhesion between carbon fibers and epoxy matrix. However, in the case of specimens using three carbon fiber layers, the obtained test results of the specimens

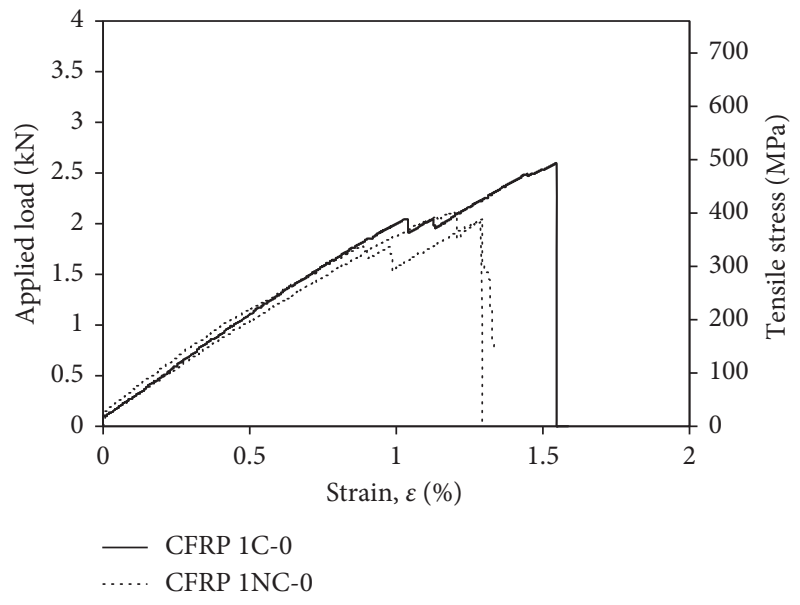

FIGURE 12: Comparison of tensile behavior of CFRP test specimens using coated and noncoated carbon fiber fabrics.

CFRP 3C-0 and CFRP 3NC-0 were not clear. This is because the peak strengths and ultimate strains of the specimens CFRP 3C-0 and CFRP 3NC-0 did not show considerable differences. Thus, further research is needed to clearly understand this behavior.

Figure 13 presents the applied load-strain and stressstrain relationships of the test specimens in the CFRP 1C series. In the case of one coating of carbon fiber layer, the increase of MWCNTs partly increased the peak strength and ultimate strain, but the trend was not significant. In Figure 14, in the case of three coatings of carbon fiber layers (CFRP 3C series), similar behaviors were also observed. The increase of the peak strength was not significant either. The phenomenon shown in Figures 13 and 14 indicates that the application of electroless copper plating (coating) could make the carbon fiber surface rough, but it might not cause a strength increase of the CFRP composites, because of the interference between coating materials and the MWCNTs in the interface of coated carbon fibers and epoxy-MWCNTs nanocomposite.

Figure 15(a) presents the tensile behavior of CFRP test specimens using one and three carbon fiber fabrics without electroless copper plating (or noncoating). In general, the 


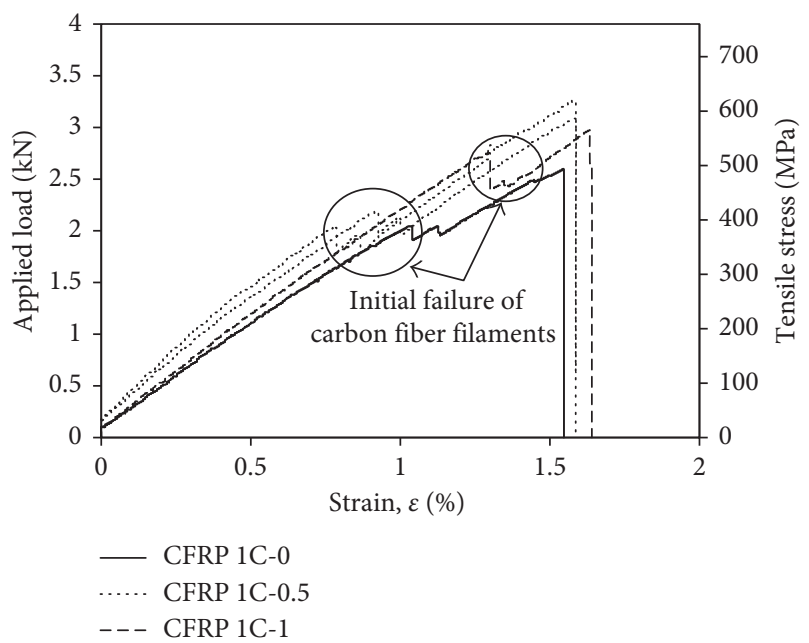

FIGURE 13: Tensile behavior of CFRP test specimens using one layer of coated carbon fibers.

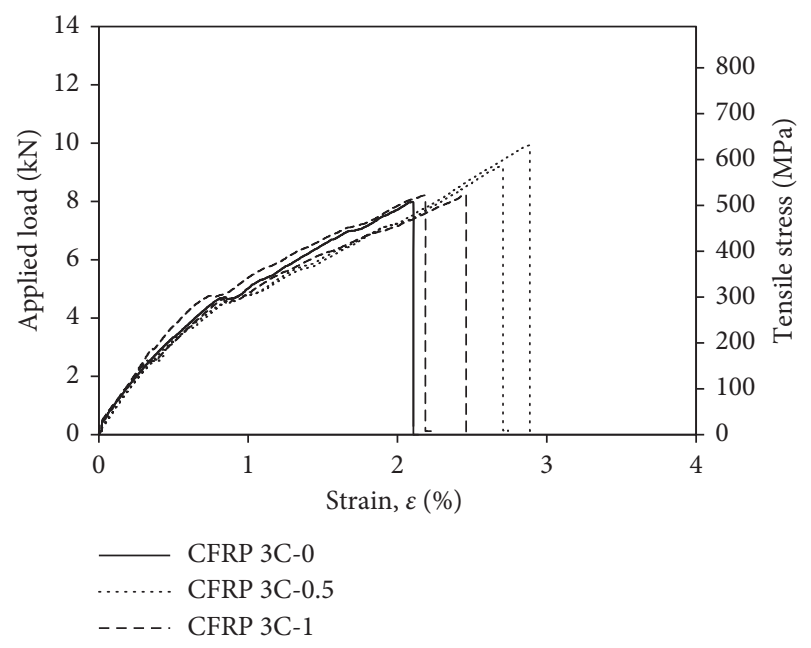

FIgURE 14: Tensile behavior of CFRP test specimens using three layers of coated carbon fibers.

use of three carbon fiber layers significantly increased the peak strength and ultimate strain, in comparison with that of one carbon fiber layer. However, the initial stiffness of the test specimens using three carbon fiber layers was slightly lower than that of the test specimens using one carbon fiber layer. Theoretically, for a perfect case of a FRP composite, the increase of tensile strength of FRP composite would be proportional to the number of carbon fiber layers, and the ultimate strain would be the same as that of FRP composite using one carbon fiber layer. However, the test results of Figure 15(a) show that the ultimate strain revealed an increase in the case of three layers of carbon fiber fabrics, compared to that of one layer of carbon fiber fabric, which indicates that there were minor cracks in the epoxy matrix, and such cracks caused slippage between the carbon fiber layers in the CFRP composite. Yan and Chouw [41] also found that increasing the number of carbon fiber layers

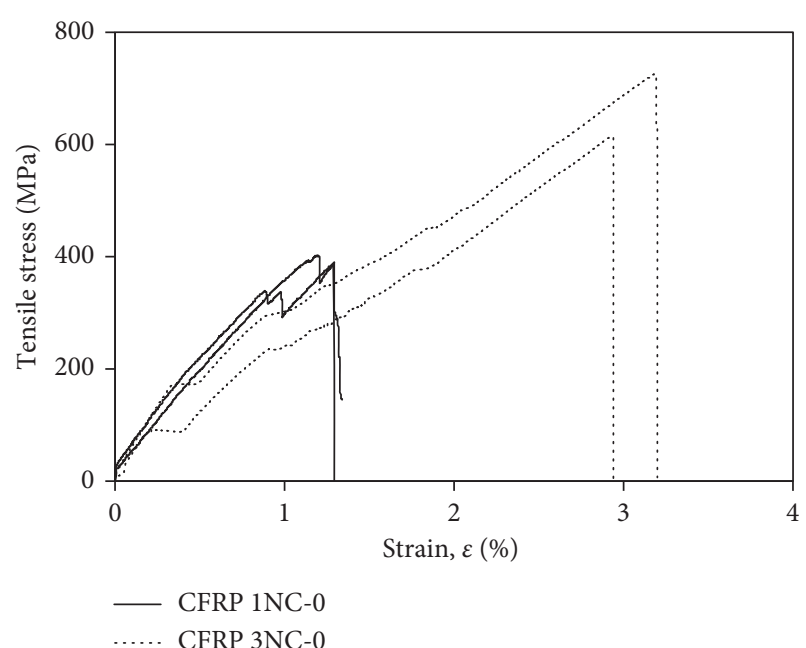

(a)

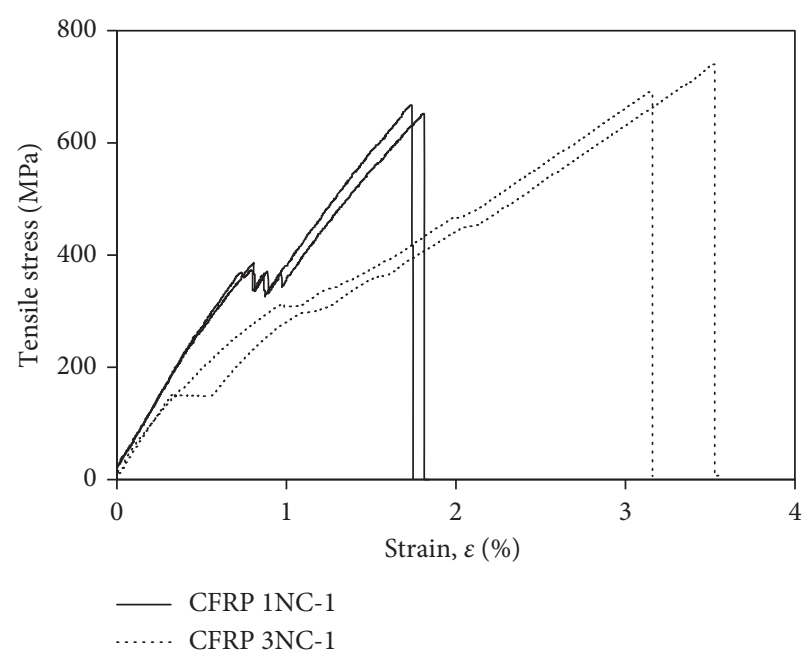

(b)

FIGURE 15: Comparison of tensile behavior of CFRP test specimens using one and three layers of noncoated carbon fibers.

could increase both the strength and the ultimate strain. Figure 15(b) shows that in the case of $1 \%$ wt. MWCNTs, the use of three layers of carbon fiber fabrics did not increase the peak strength, but did increase the ultimate strain.

Figure 16 compares the CFRP test specimens using carbon fiber fabrics after coating. In general, the use of three coatings of carbon fiber layers showed almost the same tensile strength as that of one coating of carbon fiber layer. In contrast, the ultimate strain of specimens using three carbon fiber layers significantly increased, in comparison with that of specimens using one carbon fiber layer.

3.6. Tensile Stress-Strain Response. The test results of the CFRP one-layer specimens show that the tensile stressstrain behavior of the CFRP composites in this study could be characterized by three response stages, as presented in Figure 17(a). In Stage 1, the elastic modulus can be estimated as $E_{1}$. The end of Stage 1 is determined by the appearance of cracks in the epoxy matrix accompanying rupture of part of the 


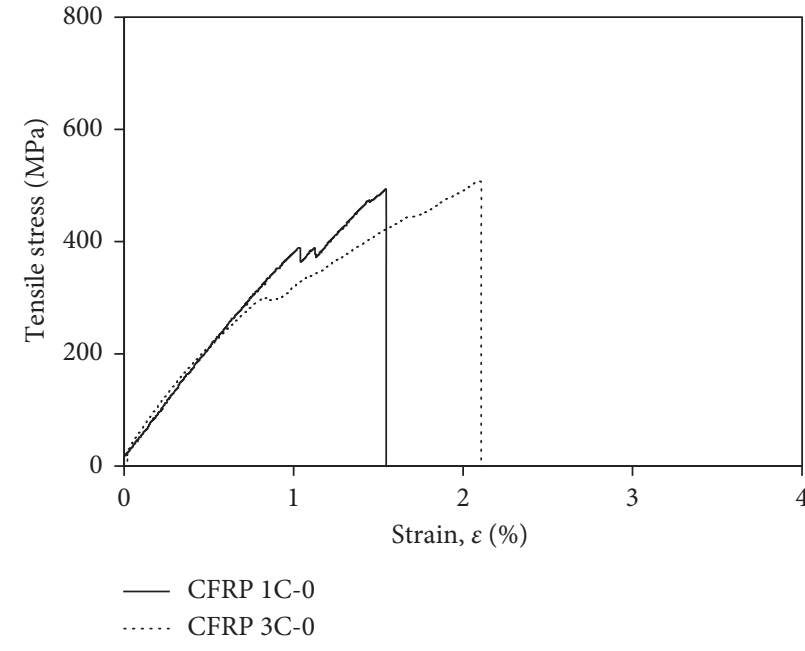

(a)

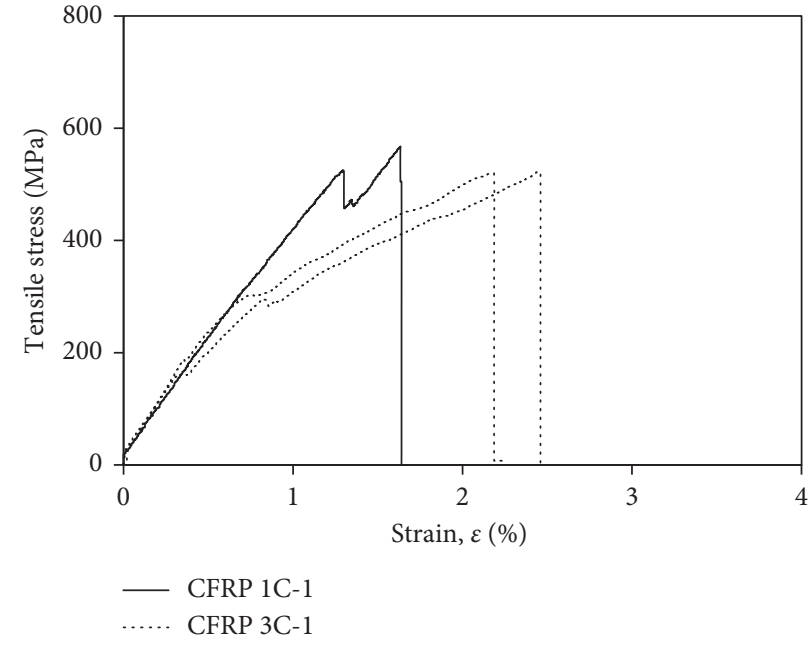

(b)

Figure 16: Comparison of tensile behavior of CFRP test specimens using one and three layers of coated carbon fibers.

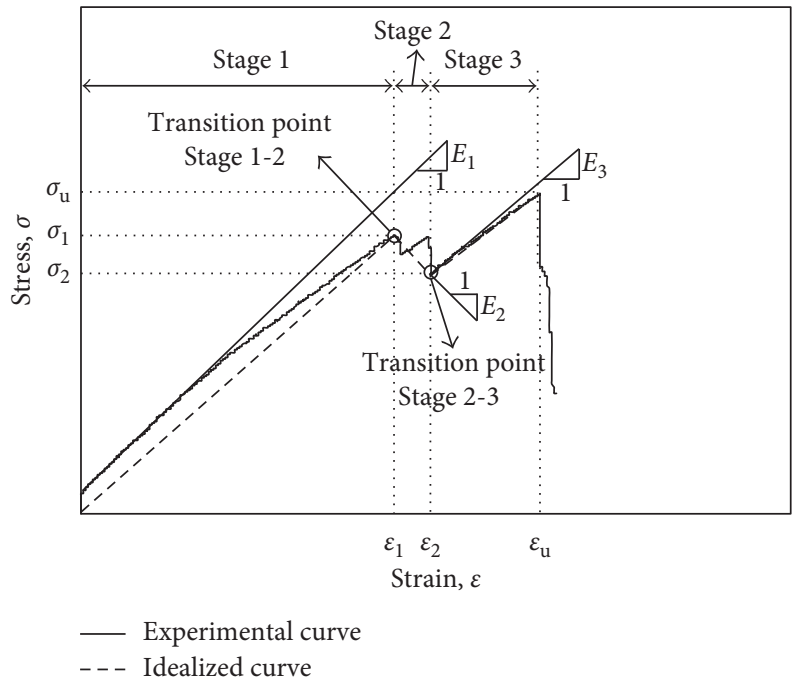

(a)

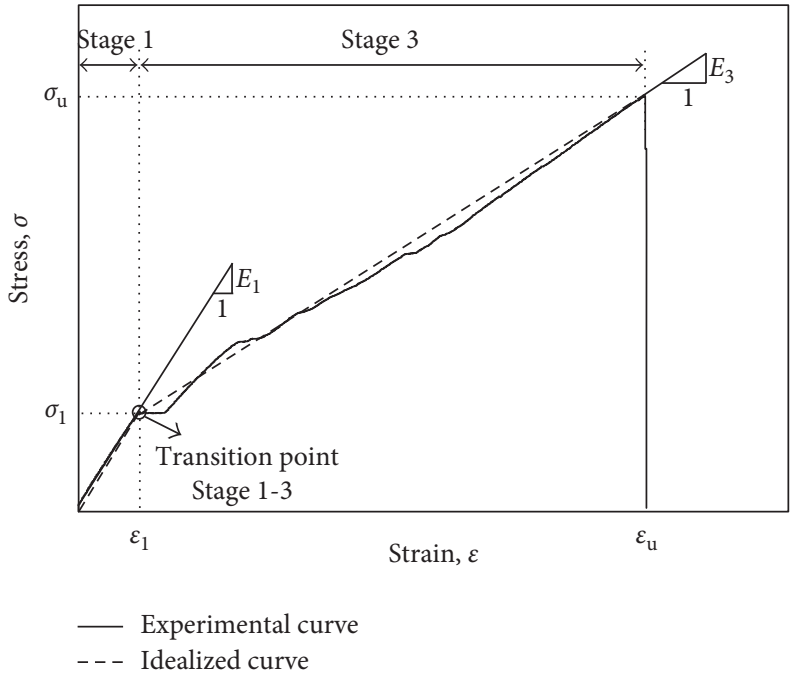

(b)

FIGURE 17: Characteristics of tensile stress-strain response curves of test specimens. (a) CFRP one-layer cases. (b) CFRP three-layer cases.

carbon fiber filaments, which causes a sudden drop in the tensile stress. The transition point between Stages 1 and 2 is designated by the stress $\sigma_{1}$ and correlative strain $\varepsilon_{1}$. In Stage 2, the tensile stress does not increase; in contrast, the deformation significantly increases. The stiffness $E_{2}$ can be determined through linear interpolation by using the proper range of test data in Stage 2. The intersection between Stage 2 and 3 is identified by a transition point with the stress $\sigma_{2}$ and correlative strain $\varepsilon_{3}$. In Stage 3, the slope of the tensile stress-strain response is defined by the stiffness $E_{3}$. Stage 3 ends with the peak strength $\sigma_{\mathrm{u}}$ and correlative ultimate strain $\varepsilon_{\mathrm{u}}$. Table 2 shows the parameter values of the trilinear response characterized in Figure 17(a).

Figure 17(b) shows the idealized bilinear tensile stressstrain response that characterized the CFRP three-layer specimens in this study. Figure 17(b) shows that Stage 2 is relatively hard to identify, and thus for simplicity, Stages 1 and 3 are the main response curves for CFRP composites using three carbon fiber layers. The absence of Stage 2 is attributed to the use of a higher amount of carbon fibers being used in combination with relatively weak epoxy matrix in this study. Table 2 also shows the parameter values of the idealized bilinear tensile stress-strain curves of CFRP composites with three carbon fiber layers.

Figure 18 compares the parameter values of the idealized stress-strain curves of the test specimens in this study. Figure 18(a) shows that for Stage 1, it is obvious that the initial stiffness of the composites using one carbon fiber layer and three carbon fiber layers was almost the same. The initial stiffness of CFRP specimens using one carbon fiber layer was 


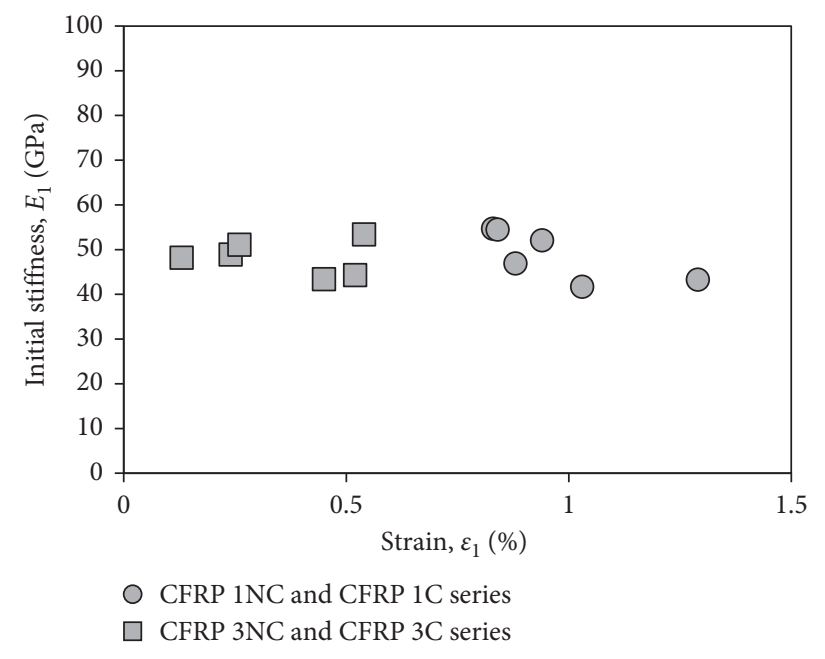

(a)

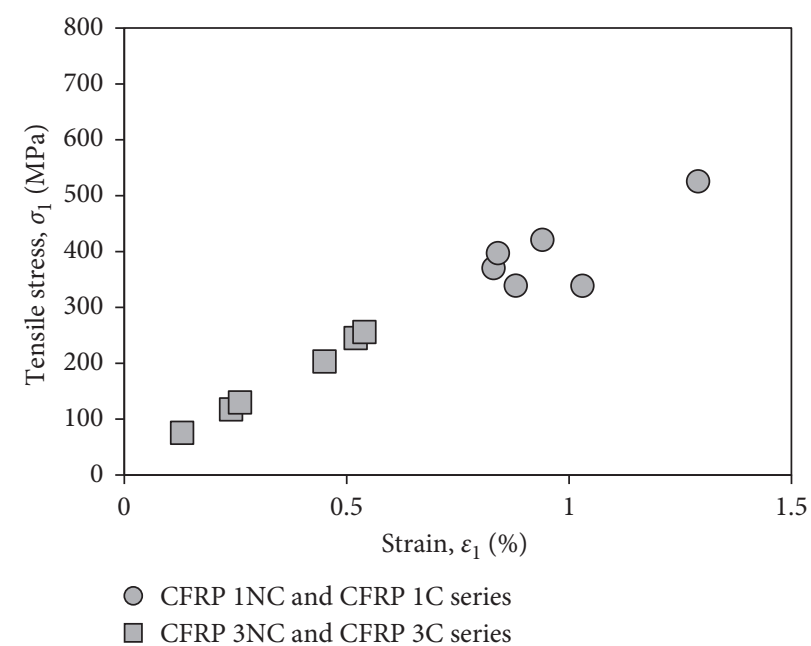

(b)

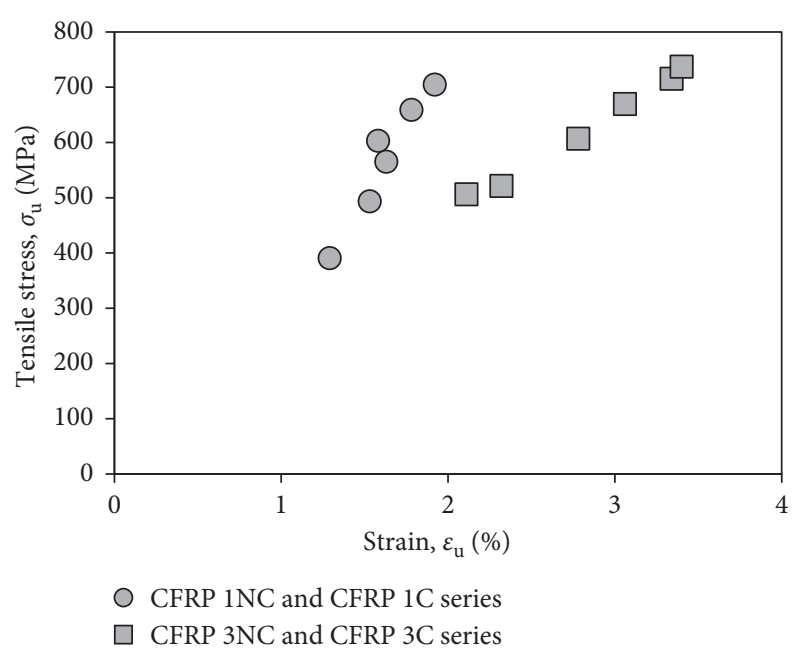

(c)

FIGURE 18: Parameter values of idealized tensile stress-strain response curves of test specimens. (a) $E_{1}-\varepsilon_{1}$ relationship. (b) $\sigma_{1}-\varepsilon_{1}$ relationship. (c) $\sigma_{\mathrm{u}}-\varepsilon_{\mathrm{u}}$ relationship.

almost the same with an average value of $48.8 \mathrm{GPa}$ and a coefficient of variation (COV) of 0.11 . The initial stiffness of CFRP specimens using three carbon fiber layers exhibited similar behavior, with a mean of $48.2 \mathrm{GPa}$, and a COV of 0.08 . Figure 18 (b) shows that the cracking strength $\left(\sigma_{1}\right)$ increased with increasing cracking strain, which is attributed to the increase of the amount of MWCNTs. Moreover, Figure 18(c) shows that in Stage 3, the ultimate strain $\left(\varepsilon_{\mathrm{u}}\right)$ and tensile stress $\left(\sigma_{\mathrm{u}}\right)$ show a linear relationship, and the composites using three carbon fiber layers exhibited higher ultimate strains, compared to those using one carbon fiber layer. It should be noted that these test parameters were determined based on very limited data in this study.

3.7. Fracture Mechanism. Figure 19 presents a typical SEM image captured from the fractured surface of test specimen CFRP 3C-1, which was fabricated by using three coated carbon fiber fabrics and epoxy matrix with $1 \%$ weight fraction of MWCNTs. Figure 19 clearly shows that after

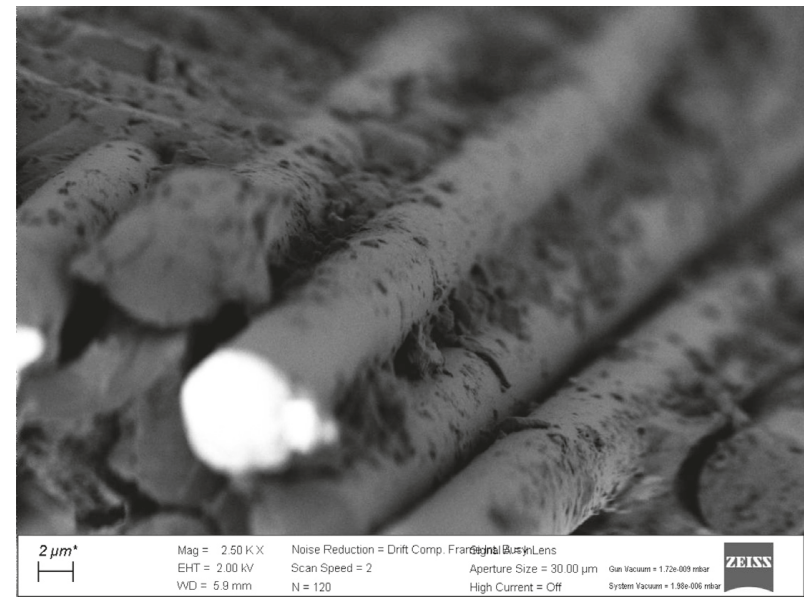

FIGURE 19: Fracture surface of test specimen CFRP 3C-1.

fracture, the epoxy matrix was pulled out; however, the carbon fiber surface was still stuck to the epoxy matrix. This fact could be attributed to the roughness of the carbon fiber 
surface after electroless copper plating. In addition, such sticking epoxy matrix also indicated that no debonding between carbon fiber and epoxy had occurred. As a result, the good mechanical bonding between the carbon fiber and epoxy matrix enhanced the tensile behavior of the test specimens, as aforementioned.

\section{Conclusions}

In this study, carbon fiber fabrics were coated by applying electroless copper plating, to investigate the effect of plating on the tensile behavior of CFRP composites. Four series of CFRP test specimens were fabricated by using a hand lay-up method, including one layer of carbon fiber fabric (CFRP 1C and CFRP 1NC), and three layers of carbon fiber fabrics (CFRP 3C and CFRP 3NC). For each test series, epoxyMWCNTs nanocomposites with various amounts of MWCNTs $(0.5,1$, and $1.5 \%$ by weight $)$ were used as adhesive material. From the test results, the primary findings are summarized as follows:

(1) SEM analysis indicated that the carbon fiber surface was successfully coated by electroless copper plating. The carbon fiber surface was significantly rough accompanying the formation of several aggregated phases, due to the excess of copper ions.

(2) The addition of MWCNTs with weight fraction up to $1.5 \%$ into the epoxy resin significantly increased the stiffness (approximately 74.5\%) and the peak strength (approximately 54.5\%) but considerably reduced the ultimate strain of the epoxy matrix by up to $70.4 \%$.

(3) In the cases of the CFRP test specimens using noncoated carbon fiber fabrics, the addition of MWCNTs significantly increased both the peak strength and the ultimate strain. By adding 1.5\% wt. MWCNTs, the peak strength and ultimate strain of CFRP 1NC-1.5 increased up to 80.5 and $48.8 \%$, respectively, and the peak strength and ultimate strain of CFRP 3NC-1.5 also increased up to 10.1 and $11.1 \%$, respectively.

(4) In the cases of CFRP test specimens using coated carbon fiber fabrics, the use of MWCNTs slightly increased the ultimate strain.

(5) In the case of application of noncoated carbon fiber fabrics, the use of three layers increased the peak strength about 1.7 times and the ultimate strain from 1.87 to 2.36 times that of the CFRP test specimens using one layer. In contrast, in the case of coated carbon fiber fabrics, the use of three layers did not increase the peak strength, but only the ultimate strain, in comparison with those of the CFRP test specimens using one layer. However in this study, these observations were based on very limited test data; thus, further research is necessary to better understand this behavior.

(6) From the test results obtained in this study, the tensile stress-strain behavior of the CFRP composites using one carbon fiber layer could be characterized by three response stages with the average initial stiffness $\left(E_{1}\right)$ of $48.8 \mathrm{GPa}$. Meanwhile, that of the CFRP composites using three carbon fiber layers could be characterized by two response stages with the average initial stiffness $\left(E_{1}\right)$ of $48.2 \mathrm{GPa}$.

\section{Data Availability}

The data used to support the findings of this study are available from the corresponding author upon request.

\section{Conflicts of Interest}

The authors declare that they have no conflicts of interest.

\section{Acknowledgments}

This research was supported by a grant (18AUDP-C14635201) from the Architecture \& Urban Development Research Program funded by the Ministry of Land, Infrastructure and Transport of the Korean Government.

\section{References}

[1] E. C. Botelho, R. A. Silva, L. C. Pardini, and M. C. Rezende, "A review on the development and properties of continuous fiber/epoxy/aluminum hybrid composites for aircraft structures," Materials Research, vol. 9, no. 3, pp. 247-256, 2006.

[2] M. Sharma, S. Gao, E. Mader, H. Sharma, L. Y. Wei, and J. Bijwe, "Carbon fiber surfaces and composite interphases," Composites Science and Technology, vol. 102, pp. 35-50, 2014.

[3] P. K. Mallick, Fiber-Reinforced Composites: Materials, Manufacturing, and Design, CRC Press, New York, NY, USA, 3rd edition, 2007.

[4] H. Guo, Y. D. Huang, L. H. Meng, L. Liu, D. P. Fan, and D. X. Liu, "Interface property of carbon fibers/epoxy resin composite improved by hydrogen peroxide in supercritical water," Materials Letters, vol. 63, no. 17, pp. 1531-1534, 2009.

[5] X. Zhang, Y. Wang, C. Lu, and S. Cheng, "Interfacial adhesive study on UHMWPE fiber-reinforced composites," Polymer Bulletin, vol. 67, no. 3, pp. 527-540, 2011.

[6] Y. Liu and S. Kumar, "Recent progress in fabrication, structure, and properties of carbon fibers," Polymer Reviews, vol. 52, no. 3-4, pp. 234-258, 2012.

[7] N. G. Ozdemir, T. Zhang, I. Aspin, F. Scarpa, H. Hadavinia, and Y. Song, "Toughening of carbon fibre reinforced polymer composites with rubber nanoparticles for advanced industrial applications," Express Polymer Letters, vol. 10, no. 5, pp. 394-407, 2016.

[8] C. Velasco-Santos, A. L. Martinez-Hernandez, and V. M. Castano, "Carbon nanotube-polymer nanocomposites: the role of interfaces," Composite Interfaces, vol. 11, no. 8-9, pp. 567-586, 2005.

[9] P. K. Agnihotri, K. K. Kar, and S. Basu, "Cohesive zone model of carbon nanotube-coated carbon fiber/polyester composites," Modelling and Simulation in Materials Science and Engineering, vol. 20, no. 3, article 035014, 2012.

[10] B. Barua and M. C. Saha, "Ultrasound assisted hybrid carbon epoxy composites containing carbon nanotubes," Journal of Engineering Materials and Technology, vol. 135, no. 1, article 011009, 2013.

[11] E. Moaseri, M. Karimi, M. Maghrebi, and M. Baniadam, "Fabrication of multi-walled carbon nanotube-carbon fiber 
hybrid material via electrophoretic deposition followed by pyrolysis process," Composites Part A, vol. 60, pp. 8-14, 2014.

[12] A. Navarro de Miranda, L. C. Pardini, C. A. Moreira dos Santos, and R. Vieira, "Evaluation of carbon fiber composites modified by in situ incorporation of carbon nanofibers," Materials Research, vol. 14, no. 4, pp. 560-563, 2011.

[13] W. Yang, R. Luo, Z. Hou, and H. Shang, "A novel preparation and properties of in-situ grown carbon nanotube reinforced carbon/carbon composites," Vacuum, vol. 132, pp. 95-105, 2016.

[14] S. P. Sharma and S. C. Lakkad, "Effect of CNTs growth on carbon fibers on the tensile strength of CNTs grown carbon fiber-reinforced polymer matrix composites," Composites Part A, vol. 42, no. 1, pp. 8-15, 2011.

[15] T. R. Pozegic, J. V. Anguita, I. Hamerton et al., "Multifunctional carbon fibre composites using carbon nanotubes as an alternative to polymer sizing," Scientific Report, vol. 6, no. 1, article 37334, 2016.

[16] T. Yan, L. Li, and L. Wang, "A simple nickel activation process for electroless nickel-phosphorus plating on carbon fiber," BioResources, vol. 8, no. 1, pp. 340-349, 2013.

[17] S. J. Park, Y. S. Jang, and K. Y. Rhee, "Interlaminar and ductile characteristics of carbon fibers-reinforced plastics produced by nanoscaled electroless nickel plating on carbon fiber surfaces," Journal of Colloid and Interface Science, vol. 245, no. 2, pp. 383-390, 2002.

[18] F. Bottger-Hiller, J. Kleiber, T. Bottger, and T. Lampke, "Multimetallic electrodeposition on carbon fibers," Materials Science and Engineering, vol. 118, article 012027, 2016.

[19] S. J. Park and Y. S. Jang, "Interfacial characteristics and fracture toughness of electrolytically Ni-plated carbon fiberreinforced phenolic resin matrix composites," Journal of Colloid and Interface Science, vol. 237, no. 1, pp. 91-97, 2001.

[20] E. J. Garcia, B. L. Wardle, and A. J. Hart, "Joining prepreg composite interfaces with aligned carbon nanotubes," Composites Part A, vol. 39, no. 6, pp. 1065-1070, 2008.

[21] E. Soliman, U. Kandil, and M. R. Taha, "Improved strength and toughness of carbon woven fabric composites with functionalized MWCNTs," Materials, vol. 7, no. 6, pp. 4640-4657, 2014.

[22] Z. Dai, F. Shi, B. Zhang, M. Li, and Z. Zhang, "Effect of sizing on carbon fiber surface properties and fibers/epoxy interfacial adhesive," Applied Surface Science, vol. 257, no. 15, pp. 6980-6985, 2011.

[23] Y. Zhou, F. Pervin, S. Jeelani, and P. K. Mallick, "Improvement in mechanical properties of carbon fabric-epoxy composite using carbon nanofibers," Journal of Materials Processing Technology, vol. 198, no. 1-3, pp. 445-453, 2008.

[24] L. Y. Yao, M. Li, Q. Wu et al., "Comparison of sizing effect of T7000 grade carbon fiber on interfacial properties of fiber/ BMI and fiber/epoxy," Applied Surface Science, vol. 263, pp. 326-333, 2012.

[25] R. E. Tucker, "81st universal metal finishing guidebook," Metal Finishing Magazine, vol. 111, no. 7, p. 415, 2013.

[26] A. M. F. Dehkharghani and M. Divandari, "Investigation of electroless copper plating on polyurethane foam, as an initial step of open cell foam production process," Transactions of the Institute of Materials Finishing (IMF), vol. 93, no. 4, pp. 186-189, 2015.

[27] H. Chen, G. Liu, C. Xu, X. Hou, and Y. Liu, "Copper@carbon fiber composites prepared by a simple electroless plating technique," Materials Letters, vol. 173, pp. 211-213, 2016.

[28] E. Soliman, M. Al-Haik, and M. R. Taha, "On and off-axis tension behavior of fiber reinforced polymer composites incorporating multi-walled carbon nanotubes," Journal of Composites Materials, vol. 46, no. 14, pp. 1661-1675, 2011.

[29] KS M ISO 527-2, Plastics-Determination of Tensile Properties-Part 2: Test Conditions for Moulding and Extrusion Plastics, Korean Standard Association, Seoul, South Korea, 2013.

[30] KS L 2522, Test Methods for Carbon Fibre Woven Fabrics, Korean Standard Association, Seoul, South Korea, 2014.

[31] KS M ISO 527-4, Plastics-Determination of Tensile Properties-Part 4: Test Conditions for Isotropic and Orthotropic Fibre-Reinforced Plastic Composites, Korean Standard Association, Seoul, South Korea, 2012.

[32] J. Jiang, C. Xu, Y. Su et al., "Influence of carbon nanotube coatings on carbon fiber by ultrasonically assisted electrophoretic deposition on its composite interfacial properties," Polymers, vol. 8, no. 8, pp. 302-312, 2016.

[33] J. Gou, C. Lu, and F. An, "Effect of electrophoretically deposited carbon nanotubes on the interface of carbon fiber reinforced epoxy composite," Journal of Materials Science, vol. 47, no. 6, pp. 2831-2836, 2012.

[34] G. Zhang, J. Karger-Kocsis, and J. Zou, "Synergetic effect of carbon nanofibers and short carbon fibers on the mechanical and fracture properties of epoxy resin," Carbon, vol. 48, no. 15, pp. 4289-4300, 2010.

[35] N. Yu and Y. W. Chang, "Effects of CNT diameter on the uniaxial stress-strain behavior of CNT/epoxy composites," Journal of Nanomaterials, vol. 2008, Article ID 834248, 6 pages, 2008.

[36] R. J. Mora, J. J. Vilatela, and A. H. Windle, "Properties of composites of carbon nanotube fibers," Composites Science and Technology, vol. 69, no. 10, pp. 1558-1563, 2009.

[37] S. Rahmanian, A. R. Suraya, M. A. Shazed, R. Zahari, and E. S. Zainudin, "Mechanical characterization of epoxy composite with multiscale reinforcements: carbon nanotubes and short carbon fibers," Materials and Design, vol. 60, pp. 34-40, 2014.

[38] A. Martone, C. Formicola, M. Glordano, and M. Zarrelli, "Reinforcement efficiency of multi-walled carbon nanotube/ epoxy nanocomposites," Composites Science and Technology, vol. 70, no. 7, pp. 1154-1160, 2010.

[39] E. Kandare, A. A. Khatibi, S. Yoo et al., "Improving the through-thickness thermal and electrical conductivity of carbon fibre/epoxy laminates by exploiting synergy between grapheme and silver nano-inclusions," Composites Part A, vol. 69, pp. 72-82, 2015.

[40] L. Dong, F. Hou, Y. Li, L. Wang, H. Gao, and Y. Tang, "Preparation of continuous carbon nanotube networks in carbon fiber/epoxy composite," Composites Part A, vol. 56, pp. 248-255, 2014.

[41] L. Yan and N. Chouw, "Experimental study of flax FRP tube encased coir fibre reinforced concrete composite column," Construction and Building Materials, vol. 40, pp. 1118-1127, 2013. 


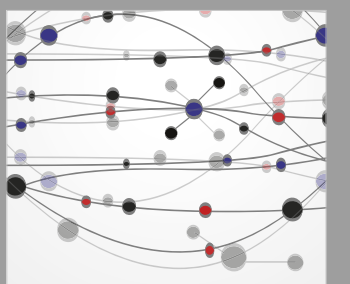

The Scientific World Journal
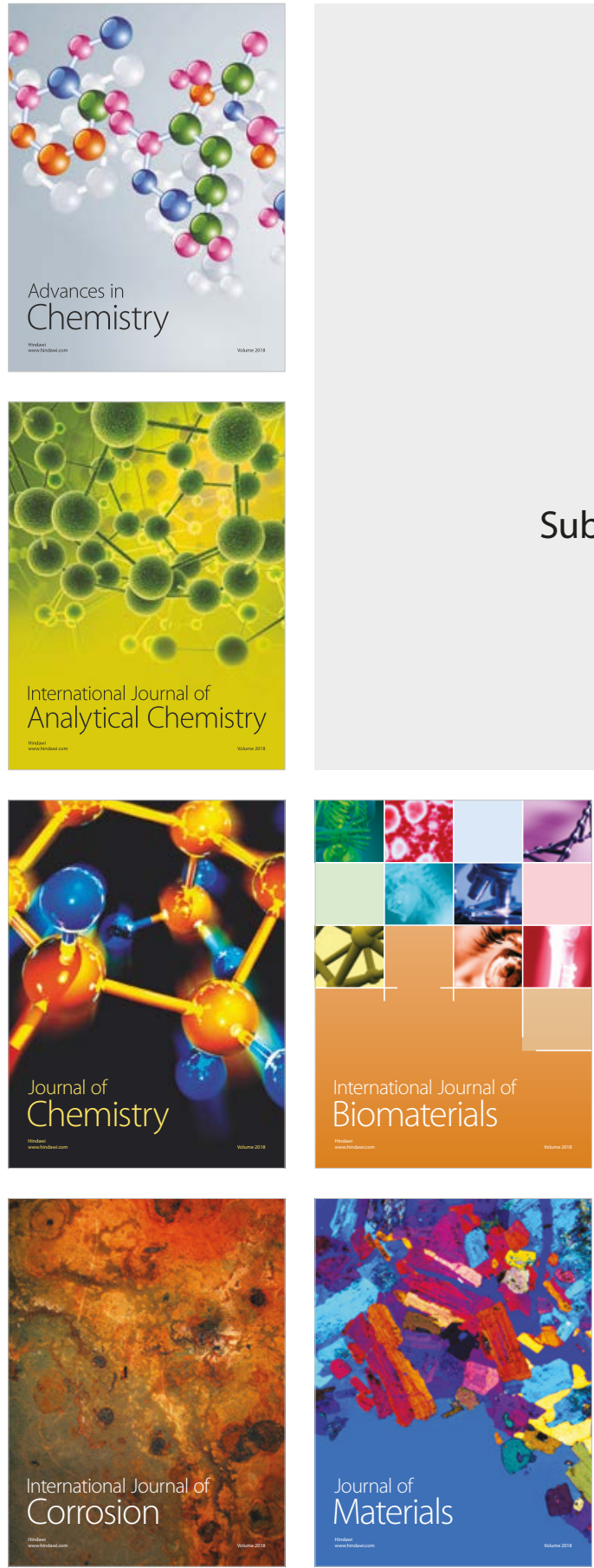

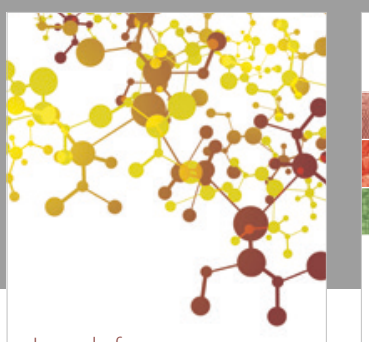

Journal of

Applied Chemistry
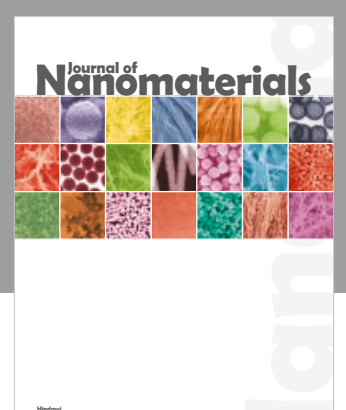

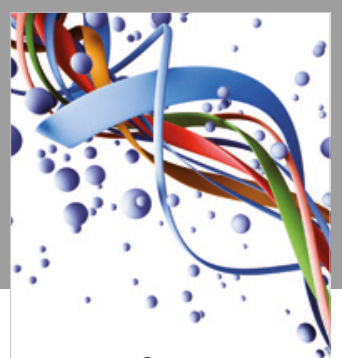

Scientifica

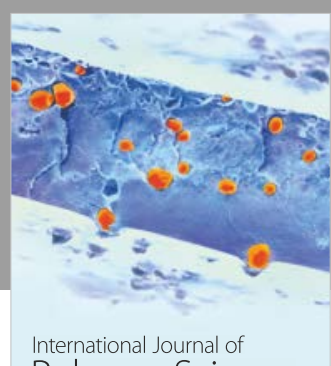

Polymer Science

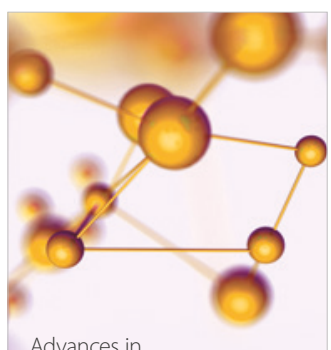

Physical Chemistry
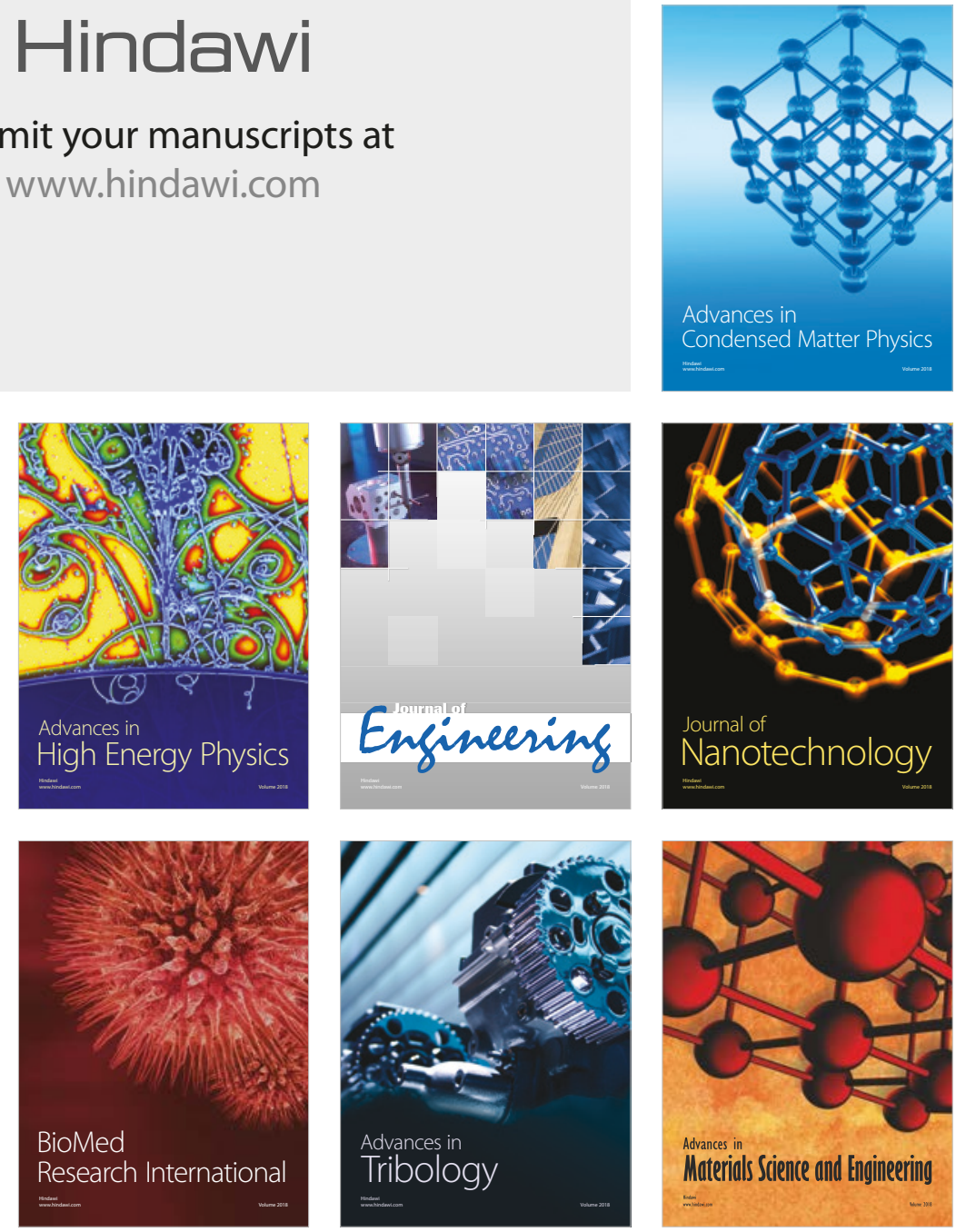